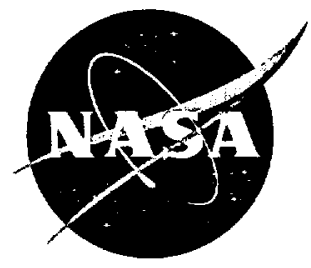

\title{
Exploratory Calibration of Adjustable- Protrusion Surface-Obstacle (APSO) Skin Friction Vector Gage
}

Raimo J. Hakkinen and Jeremy S. Neubauer

Washington University, St. Louis, Missouri

Philip J. Hamory, Trong T. Bui and Gregory K. Noffz

NASA Dryden Flight Research Center

Edwards, California 


\section{The NASA STI Program Office...in Profile}

Since its founding, NASA has been dedicated to the advancement of aeronautics and space science. The NASA Scientific and Technical Information (STI) Program Office plays a key part in helping NASA maintain this important role.

The NASA STI Program Office is operated by Langley Research Center, the lead center for NASA's scientific and technical information. The NASA STI Program Office provides access to the NASA STI Database, the largest collection of aeronautical and space science STI in the world. The Program Office is also NASA's institutional mechanism for disseminating the results of its research and development activities. These results are published by NASA in the NASA STI Report Series, which includes the following report types:

- TECHNICAL PUBLICATION. Reports of completed research or a major significant phase of research that present the results of NASA programs and include extensive data or theoretical analysis. Includes compilations of significant scientific and technical data and information deemed to be of continuing reference value. NASA's counterpart of peer-reviewed formal professional papers but has less stringent limitations on manuscript length and extent of graphic presentations.

- TECHNICAL MEMORANDUM. Scientific and technical findings that are preliminary or of specialized interest, e.g., quick release reports, working papers, and bibliographies that contain minimal annotation. Does not contain extensive analysis.

- CONTRACTOR REPORT. Scientific and technical findings by NASA-sponsored contractors and grantees.
- CONFERENCE PUBLICATION. Collected papers from scientific and technical conferences, symposia, seminars, or other meetings sponsored or cosponsored by NASA.

- SPECIAL PUBLICATION. Scientific, technical, or historical information from NASA programs, projects, and mission, often concerned with subjects having substantial public interest.

- TECHNICAL TRANSLATION. Englishlanguage translations of foreign scientific and technical material pertinent to NASA's mission.

Specialized services that complement the STI Program Office's diverse offerings include creating custom thesauri, building customized databases, organizing and publishing research results...even providing videos.

For more information about the NASA STI Program Office, see the following:

- Access the NASA STI Program Home Page at http://www.sti.nasa.gov

- E-mail your question via the Internet to help@sti.nasa.gov

- Fax your question to the NASA Access Help Desk at (301) 621-0134

- Telephone the NASA Access Help Desk at (301) 621-0390

- Write to:

NASA Access Help Desk

NASA Center for AeroSpace Information 7121 Standard Drive Hanover, MD 21076-1320 
NASA/TM-2003-210739

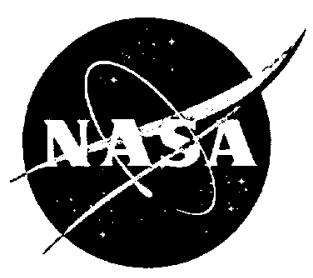

\section{Exploratory Calibration of Adjustable- Protrusion Surface-Obstacle (APSO) Skin Friction Vector Gage}

Raimo J. Hakkinen and Jeremy S. Neubauer

Washington University, St. Louis, Missouri

Philip J. Hamory, Trong T. Bui and Gregory K. Noffz

NASA Dryden Flight Research Center

Edwards, California

National Aeronautics and

Space Administration

Dryden Flight Research Center

Edwards, California 93523-0273

February 2003 


\section{NOTICE}

Use of trade names or names of manufacturers in this document does not constitute an official endorsement of such products or manufacturers, either expressed or implied, by the National Aeronautics and Space Administration.

Available from the following:

NASA Center for AeroSpace Information (CASI) 7121 Standard Drive

Hanover, MD 21076-1320

(301) 621-0390
National Technical Information Service (NTIS) 5285 Port Royal Road Springfield, VA 22161-2171

(703) $487-4650$ 


\title{
EXPLORATORY CALIBRATION OF ADJUSTABLE-PROTRUSION SURFACE-OBSTACLE (APSO) SKIN FRICTION VECTOR GAGE\#
}

\author{
Raimo J. Hakkinen $^{*}$ and Jeremy S. Neubauer ${ }^{\dagger}$ \\ Washington University, St. Louis, Missouri \\ Philip J. Hamory, ${ }^{\ddagger}$ Trong T. Bui ${ }^{\S}$ and Gregory K. Noffz ${ }^{\text {It }}$ \\ NASA Dryden Flight Research Center \\ Edwards, California
}

\begin{abstract}
$\underline{\text { Abstract }}$
The design of an adjustable-protrusion surface-obstacle (APSO) skin friction vector gage is presented. Results from exploratory calibrations conducted in laminar and turbulent boundary layers at the Washington University Low-Speed Wind Tunnel and for turbulent boundary layers at speeds up to Mach 2 on the ceiling of the NASA Glenn Research Center 8- X 6- $\mathrm{ft}$ Supersonic Wind Tunnel are also discussed. The adjustable-height gage was designed to yield both the magnitude and direction of the surface shear stress vector and to measure the local static pressure distribution. Results from the NASA test show good correlation for subsonic and low supersonic conditions covering several orders of magnitude in terms of the adopted similarity variables. Recommendations for future work in this area consist of identifying the physical parameters responsible for the disagreement between the university and NASA data sets, developing a compressibility correction specific to the APSO geometry, and examining the effect that static pressure distribution and skewed boundary layers have on the results from the APSO.
\end{abstract}

\section{Nomenclature}

APSO adjustable-protrusion surface obstacle

GRC Glenn Research Center, Cleveland, Ohio

\footnotetext{
*Professor, Mechanical Engineering Dept.: Research Scientist, AS\&M, Edwards, California; Fellow AIAA.

tGraduate Student, Mechanical Engineering Dept.

‡Instrumentation Engineer.

$\S$ Aerospace Engineer, Member AlAA

IIAerospace Engineer.

\#This work was prepared as part of the authors' official duties as employees of the U.S. Government and in accordance with 17 U.S.C. 105, and is not available for copyright protection in the United States. NASA is the owner of any foreign copyright that can be asserted for the work.
}

\begin{abstract}
WU Washington University, St. Louis, Missouri
WULSWT Washington University Low-Speed Wind Tunnel
\end{abstract}

Symbols
$A_{j}, B_{j}$
Fourier coefficients
$c_{1}$
coefficient for the power law in equation

(6a)

$c_{2}$

coefficient for the power law in equation

$h$ protrusion height of the APSO

$\mathrm{M}_{\mathrm{e}} \quad$ local boundary-layer edge Mach number

$p \quad$ pressure distribution around the circumference of the APSO

$\tilde{p} \quad$ dimensionless differential pressure

$$
=\left(\Delta p_{\max }\right) h^{2} / \rho v^{2}
$$

$\mathrm{Pe} \quad$ boundary-layer edge static pressure

$p_{\max } \quad$ peak (maximum) of the pressure distribution around the circumference of the APSO

$\mathrm{p}_{\mathrm{w}} \quad$ wall static pressure

$\Delta p \quad$ differential pressure distribution around the circumference of the APSO (defined in equation $3 \mathrm{a}$ or $3 \mathrm{~b}$ )

$\Delta p_{\max }$

peak (maximum) of the differential pressure distribution around the circumference of the APSO

$\theta$

$\theta_{p_{\max }}$

$\theta_{\Delta p_{\max }}$

$v$ location around the circumference (side) of the APSO

location at which $p_{\max }$ occurs

location at which $\Delta p_{\max }$ occurs

kinematic viscosity 


$\begin{array}{ll}\rho & \text { fluid density } \\ \tau & \text { shear stress } \\ \tilde{\tau} & \text { dimensionless shear stress }=\tau h^{2} / \rho v^{2}\end{array}$

\section{Introduction}

A great variety of experimental techniques, both direct and indirect, exists for the measurement of local skin friction. ${ }^{1}, 2,3,4$ In principle, direct measurement of the shear stress with a force-sensitive surface element would be preferred because the calibration would not depend on the characteristics of the external flow. In practice, however, the floating-element force-balance technique can be difficult to implement and is potentially subject to large errors under general flow conditions. Therefore, indirect shear stress measurement techniques have been developed.

One indirect technique is the surface obstacle method. In this method, a small obstacle is placed on the test surface, and the difference in pressure between the total pressure on the face of the obstacle and the local undisturbed static pressure is measured and interpreted as shear stress by means of a calibration under known shear stress conditions. While such a device is easier to implement, the calibration generally depends on the type of external flow. The Preston tube, which is a round pitot tube, and the Stanton tube, which is a smaller, flattened or rectangular pitot tube, are examples of surface obstacles.

Factors such as physical size, flow direction, and local pressure gradients limit the applicability of both direct and indirect techniques. As a result, there is no universally applicable method to measure skin friction. In an effort to advance the state-of-the-art, the first author developed a concept for a surface obstacle specifically targeted at reducing the limitations caused by physical size, flow direction, and pressure gradient. The result was an adjustable-height gage intended to yield both the magnitude and direction of the surface shear stress vector. This gage also has the ability to measure the local static pressure distribution.

Development began between 1993 - 1995 under the Air Force Office of Scientific Research Summer Faculty Program at Wright Laboratory, Dayton, Ohio. A simplified (1-port) proof-of-concept prototype was constructed and tested, and results were reported in reference 5 , with extensive technical background in support for the design features and anticipated calibration relationships. Work on the concept was resumed in 2000 under the sponsorship of NASA
Dryden Flight Research Center. The full 12-port gage, now called the adjustable-protrusion surface-obstacle (APSO) skin friction vector gage, was constructed and initially tested in the Washington University Low-Speed Wind Tunnel (WULSWT) for both laminar and turbulent conditions. In December 2001 the same instrument was tested in the NASA Glenn Research Center 8- X 6-ft Supersonic Wind Tunnel for turbulent conditions up to Mach 2. The primary interest in the initial tests was to verify the postulated calibration laws and to explore the direction-sensing capability of the design. Although the gage is ultimately intended to be useful in flows with pressure gradients and curved surfaces, these first tests were conducted only in flat plate boundary layers with no substantial pressure gradients.

This paper presents the design of the APSO gage, the data reduction methods, and the experimental setup and results from the Washington University (WU) and Glenn Research Center (GRC) tests.

\section{Design of the APSO Gage}

The APSO gage is based on the surface-obstacle principle described in the introduction. The obstacle in the APSO gage is a cylinder $10 \mathrm{~mm}$ in diameter (fig. 1). Twelve grooves spaced thirty deg apart were cut into the side of the cylinder and served as pressure ports. The obstacle was installed in the mount shown sketched in figure 2 and photographed in figure 3 . This mount was installed flush with the test surface. The protrusion of the obstacle into the flow (its height above the test surface) was designed to be adjustable up to $2.4 \mathrm{~mm}$. The height was set by a computer-controlled linear actuator that pushed the obstacle outwards from the test surface; a spring kept the base of the obstacle in contact with the actuator. The Washington University School of Medicine Machine Shop manufactured the gage, using drawings prepared at Wright Laboratory.

The grooves $(7.6 \mathrm{~mm}$ long, $0.5 \mathrm{~mm}$ deep, and $0.5 \mathrm{~mm}$ wide) direct the pressure from the side of the obstacle to the $0.5 \mathrm{~mm}$-diameter horizontal channels inside the mount. These channels were further connected to standard steel pressure tubing to transmit the pressures to appropriate sensor instrumentation. To minimize leakage between the pressure ports, the gap between the obstacle and the mount was $0.01 \mathrm{~mm}$. The effect of air leakage in the gap was examined by filling the gap with grease during one low-speed test. There were no measurable differences in pressure readings between the tests with and without grease. In physical terms, therefore, it was assumed that the low rate of the 
leakage flow, which is primarily driven by the pressure differences between adjoining grooves, does not significantly affect the observed port pressures. Furthermore, because any residual effects would also be included in calibration data, all subsequent tests were conducted without this grease sealing.

When the obstacle is flush with the test surface, the groove design makes it possible for the APSO gage to read local static pressures. This feature gives the APSO gage certain advantages over other surface-obstacle instruments: (1) Static pressure is read at the same location as the total pressure. In contrast, for the Preston tube, static pressure is obtained near to, but not at the location of, the Preston tube. For flows with significant pressure gradients, this capability could be helpful in reducing measurement errors. Of course, because the total and static pressures are not measured at the same time, flow conditions must remain the same for the pressure difference to be valid. (2) With 12 ports, the static pressure distribution could potentially be useful for measuring shear stress in complex configurations, such as on non-planar surfaces.

The adjustable height of the obstacle was expected to be an advantage for the following additional reasons: (1) The obstacle height can be set to the minimum required to sense the differential pressure with satisfactory accuracy, and therefore the flow in the boundary layer is not disturbed more than absolutely necessary. (2) The effects of hostile environments, such as the high temperatures of hypersonic flows, could be minimized by retracting the obstacle before and after measurement. (3) Measurements taken at multiple protrusions above the surface make it possible to distinguish between laminar and turbulent boundary layers.

\section{Data Reduction Methods}

Let $\theta$ denote the location around the circumference (side) of the obstacle, and let $h$ be the protrusion height of the obstacle above the surface. The continuous pressure distribution, $p$, around the circumference of the obstacle, is a function of $\theta$ and $h$. For a given $h$, an approximation of $p$ can be obtained from the following Fourier series:

$$
p(\theta)=0.5 A_{0}+\sum_{j=1}^{6} A_{j} \cos j \theta+\sum_{j=1}^{5} B_{j} \sin j \theta
$$

where the $12 A$ and $B$ terms are the Fourier coefficients obtained from the measurements at the 12 pressure ports spaced 30 deg apart. Let $p_{\max }(h)$ represent the peak of the pressure distribution at height $h$ and let $\theta_{p_{\max }}(h)$ be the location at which $p_{\max }(h)$ occurs. The value of $\theta_{p_{\max }}$ can be found by setting equation (2), the derivative of equation (1), equal to zero and solving for $\theta$.

$$
d p(\theta) / d \theta=-\sum_{j=1}^{6} A_{j} j \sin j \theta+\sum_{j=1}^{5} B_{j} j \cos j \theta
$$

As mentioned in the introduction, the objective in using a surface obstacle is to correlate shear stress to the difference between the pressure on the face of a small obstacle and the local undisturbed static pressure. For the APSO, the pressure difference $\Delta p$ was obtained from either equation (3a) or (3b).

$$
\begin{gathered}
\Delta p(\theta, h)=p(\theta, h)-p(\theta, h=0) \\
\text { or } \\
\Delta p(\theta, h)=p(\theta, h)-p\left(\theta=0^{\circ}, h=0\right)
\end{gathered}
$$

Then, for each $h, \Delta p(\theta)$ was substituted for $p(\theta)$ in equations (1) and (2) to obtain $\Delta p_{\max }$ and $\theta_{\Delta p_{\max }}$.

Equation (3a) uses the static pressure distribution as the reference and should be interpreted in this way: $\Delta p$ at each port $\theta$ is obtained by using the pressure reading at $h=0$ for that port. Equation (3b) uses only the front-port $\left(\theta=0^{\circ}\right)$ static pressure as the reference for all ports. Data from a WU test case shows that equations (3a) and (3b) yield similar results for most values of $h$. Unless otherwise stated, the reader should assume that the front-port-only reference (equation $3 b$ ) was used.

Universal calibrations have been obtained for Stanton tubes and Preston tubes by using nondimensional variables. In the same way, $\Delta p_{\max }$ and the surface shear stress $\tau$ are nondimensionalized as follows:

$$
\tilde{p}=\left(\Delta p_{\max }\right) h^{2} / \rho v^{2}
$$

and

$$
\tilde{\tau}=\tau h^{2} / \rho v^{2}
$$

where $\rho$ and $v$ are the density and kinematic viscosity, respectively, at the wall. Based on the Preston-tube and related databases reviewed in reference 5 and based on results obtained previously 
with the 1-port APSO gage prototype, it was expected that $\tilde{p}$ would asymptotically reach

$$
\tilde{p}=c_{1} \tilde{\tau}^{1.13}
$$

at large values of $\tilde{\tau}(\tilde{\tau}>12600)$ and reach

$$
\tilde{p}=c_{2} \tilde{\tau}^{5 / 3}
$$

at small values of $\tilde{\tau}(\tilde{\tau}<200)$. Because of geometric differences, $c_{1}$ and $c_{2}$ are coefficients whose values are not expected to be the same for the APSO as for Preston tubes $\left(c_{1}=35.55\right)$ or Stanton tubes $\left(c_{2}=1.117\right)$.

For $\tilde{\tau}<1000$, practical cases of both laminar and turbulent boundary layers are found and because of the fundamental differences in the near-wall environment, their calibrations do not coincide. ${ }^{6}$

Small static pressure gradients at the location of the APSO gage were observed in both WU and GRC data. On the basis of the extensive study of error for Preston tubes, ${ }^{7}$ the impact of those pressure gradients on determining $\Delta p_{\max }$ in the present measurements is believed to be negligible. However, the static pressure distribution does impact the determination of $\theta_{\Delta p_{\max }}$ at small protrusions. This will be discussed with the Washington University results.

Quantifying the accuracy of $\theta_{p_{\max }}$ remains to be done in the future. At the present time, the accuracy is assumed to be well within $\pm 5 \mathrm{deg}$. Note that the pressure distribution obtained from the Fourier series procedure passes exactly through each measured point, and because of the rounded shape of the distribution around the peak, $p_{\max }$ is not significantly affected by errors in $\theta_{p_{\max }}$.

\section{Testing at Washington University Low-Speed Wind Tunnel (WULSWT)}

\section{Experiment Setup}

To verify the postulated calibration laws (equations $6 \mathrm{a}$ and $6 \mathrm{~b}$ ) in incompressible flow for both laminar and turbulent boundary layers, tests were conducted at the WULSWT (fig. 4). The tunnel has a 2- X 2- X 5-foot (610-X 610-X $1524-\mathrm{mm})$ test section and is capable of operating from Mach 0 to Mach 0.2 . The test section is equipped with a transparent flat plate having a semi-elliptical leading edge that joins the $13-\mathrm{mm}$ thick flat portion with a continuous-curvature spline to minimize transition-inducing disturbances at low speeds. The APSO gage was mounted $1118 \mathrm{~mm}$ from the physical leading edge, and the laminar boundary layer velocity profile at this location was verified to correspond to a sharp-leading-edge Blasius solution ${ }^{8}$ with an effective run distance of slightly less than $1118 \mathrm{~mm}$. The turbulent test conditions at higher velocities resulted from natural transition. The APSO gage was tested at one laminar and two turbulent boundary layer conditions summarized in Table 1 , below.

The APSO gage was mounted $50.8 \mathrm{~mm}$ to the left of the tunnel center line and was oriented such that the axis defined by $\theta=0$ deg and $\theta=180 \mathrm{deg}$ was parallel to the tunnel center line with $\theta=0$ deg on the windward side of the obstacle. The direction of increasing $\theta$ was clockwise (toward the center line of the tunnel).

Table 1. Summary of WULSWT test conditions.

\begin{tabular}{lccccc}
\hline \hline $\begin{array}{l}\text { Boundary } \\
\text { layer state }\end{array}$ & $\begin{array}{c}\text { Freestream } \\
\text { velocity, } \mathrm{m} / \mathrm{sec}\end{array}$ & $\begin{array}{c}\text { Reynolds number } \\
\text { based on length } \\
\text { from leading edge }\end{array}$ & $\begin{array}{c}\text { Skin } \\
\text { friction } \\
\text { coefficient }\end{array}$ & $\begin{array}{c}\text { Shear } \\
\text { stress, Pa }\end{array}$ & $\begin{array}{c}\text { Boundary layer } \\
\text { thickness, mm (based } \\
\text { on 99 percent of } \\
\text { freestream velocity) }\end{array}$ \\
$\begin{array}{l}\text { Laminar } \\
\begin{array}{l}\text { Turbulent } \\
\text { (Case 1) }\end{array}\end{array}$ & 7.64 & 512,000 & 0.000928 & 0.0311 & 7.6 \\
$\begin{array}{l}\text { Turbulent } \\
\text { (Case 2) }\end{array}$ & 18.9 & $1,350,000$ & 0.00312 & 0.657 & 21.8 \\
\hline
\end{tabular}


A computer-driven precision actuator was used to set and read the height of the obstacle in selected increments from 0 to $2.4 \mathrm{~mm}$ with an accuracy of $\pm 0.005 \mathrm{~mm}$. Pressure tubes from the 12 ports were connected through a mechanically switched pressure scanner to a $\pm 700 \mathrm{~Pa}$ variable-reluctance differential pressure transducer referenced to local static pressure. Accuracy for the transducer was \pm 0.25 percent of full scale. Pressure readings were acquired at 100 samples per sec, and their averages and standard deviations were automatically computed over a total period of five sec.

Boundary layer profiles were obtained by simultaneously traversing a pitot probe and an adjacent hot-wire probe. Reference skin friction values accurate to \pm 5 percent were obtained for the laminar case by matching the measured velocity profiles with the Blasius solution ${ }^{8}$, adjusted for best fit by modifying the distance from the leading edge (because of the modified shape of this plate leading edge). The result yielded a skin friction coefficient based on the velocity gradient at the surface. For the turbulent cases, the skin friction coefficient was obtained by matching the velocity profiles to the logarithmic-law region using the Clauser method. ${ }^{9}$

\section{Turbulent Results}

Figure 5 shows the Fourier-fitted differential pressure distribution, $\Delta p(\theta)$, at protrusion heights of $0,0.2,0.8$, and $2.4 \mathrm{~mm}$ for the second turbulent flow case. Uncertainties are given at the 95 percent confidence level. Non-zero values at $h=0$ indicate the undisturbed static pressure distribution on the flat test surface.

Figure 6 shows the maximum differential pressure, $\Delta p_{\max }$, obtained at each protrusion height tested. Results for $\Delta p_{\max }$ using both the static pressure distribution reference (equation $3 a$ ) and the front-port-only reference (equation $3 \mathrm{~b}$ ) are plotted. The results are within 0.3 percent of each other and are accepted as indistinguishable.

Figure 7 shows $\theta_{\Delta p_{\max }}$ obtained using both static pressure references. No $\theta_{\Delta p_{\max }}$ is shown at $h=0$ for the static pressure distribution reference case because $\Delta p$ in that case is zero by definition. In contrast, for the front-port-only reference case, $\theta_{\Delta p_{\max }}$ at $h=0$ is large. At larger protrusion heights, the difference between the two cases essentially disappears. Therefore, the difference in $\theta_{\Delta p_{\max }}$ values between the two cases is interpreted to be the result of the inherent static pressure distribution on the test surface being added to the APSO total pressure distribution in the range where both are of a comparable order of magnitude. It is therefore evident that the presence of the static pressure distribution on a test surface must be considered as a source of error that may significantly limit the minimum protrusion at which reliable $\theta_{\Delta p_{\max }}$ results can be obtained. In the case shown in figure 7 , the limit would be approximately $0.3 \mathrm{~mm}$.

Figure 8 shows the nondimensional variables, $\tilde{p}$ and $\bar{\tau}$, plotted against each other for both turbulent cases. In this plot the width and height of each symbol represents the \pm 5 percent uncertainty in $\tau$ and the uncertainty in $\Delta p_{\max }$, respectively. Uncertainties in $\rho$ and $v$ were not considered in this report. The 1.13- and 5/3-power laws are shown as well, with $c_{1}$ equal to $31.7(+3.8$ or $-3.5)$ and $c_{2}$ equal to $0.71(+0.17$ or -0.22$)$, respectively. Although the data from the two cases can be seen to agree at small and large values of $\tilde{\tau}$, there is a disagreement at middle values $\left(10^{3}<\tilde{\tau}<10^{4}\right)$. This disagreement indicates that the nondimensional calibration may not account for all the relevant physical parameters. The GRC tests were conducted in part to identify other relevant physical parameters, and the combined data base will be discussed later in the paper.

\section{Laminar Results}

Figure 9 shows the Fourier-fitted differential pressure distribution, $\Delta p(\theta)$, at protrusion heights of 0.8 and $2.0 \mathrm{~mm}$ for the laminar flow case. Figure 10 shows $\Delta p_{\max }$ plotted for all values of $h$ in dimensional form and figure 11 shows it in nondimensional form with turbulent results. In the latter figure the 5/3-power-law asymptote is included using $c_{2}=1.9(+0.8$ or -0.6$)$. For $\bar{\tau}>200$, the data points rise above the asymptote in a manner characteristic of laminar boundary layers. This behavior, plus the larger value of $c_{2}$ than for the turbulent cases, indicates that the adjustable-height feature of the APSO gage could be used to detect the state of the boundary layer and could provide a measurement of skin friction in both kinds of boundary layers. 


\section{Testing at NASA Glenn Research Center 8- X 6-ft Supersonic Wind Tunnel}

\section{Experiment Setup}

To verify the postulated calibration laws in compressible flows, testing was done at the NASA Glenn Research Center (GRC) 8- X 6-ft (2438- X $1829-\mathrm{mm}$ ) Supersonic Wind Tunnel. The tunnel is capable of providing turbulent conditions from Mach 0 to Mach 0.1 and Mach 0.25 to Mach 2. ${ }^{10,11}$ The APSO gage was mounted in the ceiling of the solid-wall supersonic test section, $107.95 \mathrm{~mm}$ from the tunnel center line, as shown toward the left of figures 12 and 13. The gage was oriented such that the axis defined by $\theta=0 \mathrm{deg}$ and $\theta=180 \mathrm{deg}$ was parallel to the tunnel center line with $\theta=0 \mathrm{deg}$ on the windward side. The direction of increasing $\theta$ was clockwise (toward the center line of the tunnel).

Reference skin friction values accurate to \pm 5 percent were obtained by matching boundary layer velocity profiles to the logarithmic-law region using the Clauser method. ${ }^{9}$ The boundary layer velocity profiles were obtained in two parts: (1) using the large boundary layer rake shown in figure 12 to obtain velocity measurements from 6.4 to $445 \mathrm{~mm}$ above the wall and (2) using a smaller rake on the previous day to obtain additional velocity measurements closer to the wall, from 1.0 to $70 \mathrm{~mm}$ above the wall. This two-part technique for obtaining combined velocity profiles and skin friction values has been used previously. "

Three Preston tubes with outer diameters of $3.18 \mathrm{~mm}$ served as secondary reference measurements. Using the Bradshaw and Unsworth method ${ }^{12}$ with the Allen ${ }^{* *}$ correction, ${ }^{13}$ the Preston tubes gave skin friction results that were consistent with those obtained from the Clauser method. One Preston tube was located $31.75 \mathrm{~mm}$ to the left of the APSO. Another Preston tube was located $139.70 \mathrm{~mm}$ to the right of the tunnel center line. A third Preston tube was located $38.10 \mathrm{~mm}$ aft of the center line of the APSO gage. The results from this third Preston tube were consistent with the other two as long as the APSO protrusion height was in the range of $-0.20 \mathrm{~mm} \leq h \leq 0.20 \mathrm{~mm}$.

For the purpose of reducing the boundary-layer rake and Preston tube data, the local static pressure was assumed to be constant across the boundary layer and

\footnotetext{
**Equation (7) in ref 13 has a typographical error in the report, placing the decimal at 2.37 instead of 23.7 , as was intended. Ref 12 shows this number correctly in equation (6).
}

equal to the boundary-layer edge static pressure $p_{\mathrm{e}}$. The procedure used for calculating $\mathrm{p}_{\mathrm{e}}$ depends on whether the flow is subsonic or supersonic.

For subsonic conditions, the three measurements of wall static pressure, $p_{w}$, from the wall static pressure ports $1-3$, agree with each other to within 1 percent, and $\mathrm{p}_{\mathrm{e}}$ was assumed to be the arithmetic average of these three $p_{w}$ measurements. The local boundary-layer edge Mach number, $M_{e}$, was then computed from the pitot pressure measurement from the top pitot tube of the large boundary-layer rake (the top pitot pressure) and $\mathrm{Pe}_{\mathrm{e}}$ using the isentropic relation. The computed $M_{e}$ values agree with the reference wind tunnel Mach numbers to within 2 percent for all subsonic conditions.

For supersonic conditions, the three $\mathrm{P}_{\mathrm{w}}$ measurements differ from each other as much as 7.5 percent, and $\mathrm{pe}_{\mathrm{e}}$ was calculated using a different procedure. $M_{e}$ was computed from the ratio of the top pitot pressure to the wind-tunnel stagnation pressure using the normal shock relation. The computed $M_{e}$ values agree with the reference wind-tunnel Mach numbers to within 4 percent for all supersonic conditions. Then $\mathrm{Pe}_{\mathrm{e}}$ was computed from the wind-tunnel stagnation pressure and $M_{e}$, using the isentropic relation. The computed $p_{e}$ values are consistently $2-5$ percent lower than the average of the $p_{w}$ measurements. For a flat-plate boundary layer, the static pressure should be constant across the boundary layer. The higher $\mathrm{p}_{\mathrm{w}}$ measurements, as well as the large scattering of these values (as mentioned earlier), indicate possible local wall interference effects at supersonic conditions. Using the calculated $\mathrm{p}_{\mathrm{e}}$ values instead of the measured wall static pressures in the boundary-layer analysis avoids errors that the interference would introduce.

Two wall temperature measurements (thermocouples 1 and 2) are shown in figure 13. These measurements were also used to obtain flow properties at the wall.

Figures 12 and 13 also show six hot films on ceramic substrates. They were operated in conjunction with temperature-compensating elements mounted on the two larger ceramic substrates $38.10 \mathrm{~mm}$ downstream. A skin-friction calibration for the hot-film sensors was another principal objective of the GRC tests. The design of these hot films and the calibration obtained are the subject of a separate paper in work by Gregory $K$. Noffz et al at NASA Dryden.

Pressure and wall temperature readings were collected by the GRC 8- X 6-ft Supersonic Wind Tunnel data system in records lasting $10 \mathrm{sec}$ at two samples per 
sec. A \pm 35000 -Pa differential module was used for the APSO gage pressure measurements. For Mach numbers below $0.75, a \pm 7000$-Pa differential module was used in addition to the 35000-Pa module. Uncertainty for the smallest pressure readings was \pm 4 percent of the reading. Uncertainty for the highest pressure readings was less than \pm 1 percent of the reading.

As in the WU tests, a computer-controlled linear actuator was used to set and read the protrusion heights on demand over a range of $-0.5 \mathrm{~mm}$ to $2.4 \mathrm{~mm}$. Because the temperature in the test section and on the backside of the ceiling could reach $160^{\circ} \mathrm{F}$ or higher, the APSO gage actuator was fitted with a cooling jacket that kept the air temperature around the actuator in the range of 60 to $100^{\circ} \mathrm{F}$. In this temperature range, the bidirectional repeatability of the actuator was specified by the manufacturer to be $\pm 0.0015 \mathrm{~mm}$.

Actuator position was calibrated in situ before the tests using a micrometer with an accuracy of $\pm 0.005 \mathrm{~mm}$; but for reasons that have not yet been determined, offsets in $h$ on the order of $0-0.05 \mathrm{~mm}$ were evident beginning with the first test condition. For this reason $\Delta p$ was computed using the front-port-only reference (equation $3 b$ ).

\section{$\underline{\text { Results }}$}

An extensive collection of APSO circumferential pressure distributions for the complete obstacle protrusion range of $-0.5 \mathrm{~mm}$ to $2.4 \mathrm{~mm}$ was obtained on December 6, 2001. Measurements were made at wind tunnel Mach numbers of $0.26,0.30,0.40,0.50,0.65$, $0.75,0.95,1.19,1.36,1.56,1.76$ and 1.96. Boundary layer thicknesses ranged from approximately 81 to $142 \mathrm{~mm}$, and shear stress levels up to $88 \mathrm{~Pa}$ were observed. Data from the Mach 0.26 and 1.56 conditions are shown in detail. The remainder are summarized in the plots of nondimensional variables.

Figures 14 and 15 show $\Delta p(\theta)$ at protrusion heights of $0,0.2,1.2$, and $2.4 \mathrm{~mm}$ for Mach numbers of 0.26 and 1.56 , respectively.

Figure 16 shows $\theta_{\Delta p_{\max }}$ obtained for each protrusion height tested at Mach 0.26 and 1.56. Data collected with the obstacle submerged $(h<0)$ are also shown in the plot and were used to confirm the flush position. Slightly above the surface, $\theta_{\Delta p_{\max }}$ reaches approximately $-13 \mathrm{deg}$ at $h=0.2 \mathrm{~mm}$ for the Mach 0.26 condition before achieving a final value of -7 to $-9 \mathrm{deg}$ when further above the surface. This profile was typical for the various Mach numbers although the magnitude of the excursions varied somewhat as can be seen in the figure.

In the discussion for figure 7 , it was noted that the influence of the local static pressure distribution on $\theta_{\Delta p_{\max }}$ is large at small protrusions and diminishes as $h$ increases. In figure $16, \theta_{\Delta p_{\max }}$ is seen to change at high protrusions as well. This change is thought to be the result of velocity vector skewing in the boundary layer at the test location. Further measurements in turbulent boundary layers with known skewing are planned in order to investigate this phenomenon.

Figures 17 and 18 show the $\Delta p_{\max }$ plotted against protrusion height for Mach 0.26 and 1.56, respectively.

Figure 19 shows $\tilde{p}$ plotted against $\tilde{\tau}$ for conditions from Mach 0.26 to Mach 1.19 as well as for the WU turbulent cases for reference. The consistency of the GRC data over several orders of magnitude in $\tilde{p}$ and $\tilde{\tau}$ is seen to be excellent. The following equation serves as a correlation:

$$
\begin{aligned}
\tilde{p} & =0.18 \tilde{\tau}^{5 / 3} e^{-0.0175 \tilde{\tau}^{0.45}} \\
& +25 \tilde{\tau}^{1.13}\left(1-e^{-0.000029 \tilde{\tau}^{0.9}}\right)
\end{aligned}
$$

This equation is consistent with equations (6a) and (6b) using 25 for $c_{1}$ and 0.18 for $c_{2}$ and exponentials, to gradually bend from the $5 / 3$ asymptote to the 1.13 asymptote. Dotted lines representing \pm 20 -percent bands around this correlation are shown as well

Because the same APSO gage was used in both the WU and GRC tests, it is suspected that some geometric scale parameter (such as boundary layer thickness) accounts for the disagreement between the results from the two facilities. Exploratory studies using computational fluid dynamics are planned for clarification of this matter.

Figure 20 shows the GRC data for Mach numbers above 1.19 with the lower Mach number GRC data. At these conditions the effect of compressibility is large enough to be noticed in the plot. Relatively simple correction procedures have been developed ${ }^{5}$ for reducing compressible Preston-tube data to the calibration established for low-speed flows where compressibility effects are not significant. However, applications of Preston-tube-type compressibility 
corrections to the APSO data were not adequate, most likely because of the different geometry of the APSO as compared to the Preston-tube of the same height. The development of compressibility correction procedures for the APSO gage is a primary subject for future research.

\section{Concluding Remarks}

The Adjustable-Protrusion Surface-Obstacle (APSO) Skin Friction Vector Gage was developed specifically to reduce shear stress measurement limitations caused by physical size, flow direction, and pressure gradients. The tests reported herein were conducted to verify the postulated calibration laws and to explore the direction-sensing capability of the device. The most valuable result of this project is the extensive, close correlation of all subsonic and low supersonic data obtained at the NASA Glenn Research Center 8- X 6-ft Supersonic Wind Tunnel, covering several orders of magnitude in terms of the adopted similarity variables. This correlation verifies the functional form of the specific similarity laws in both the low and high regions of $\tilde{\tau}$, the dimensionless shear stress parameter.

The next level of research involves: First, studying various combinations of obstacle geometry and boundary layer characteristics to identify the physical parameters responsible for the disagreement between the Washington University and Glenn Research Center data sets. Second, developing a compressibility correction suitable for the APSO geometry. Third, examining the effect of static pressure distribution on the APSO results at small deflections. Fourth, examining APSO results in the presence of known skewed boundary layers.

\section{$\underline{\text { References }}$}

${ }^{1}$ Rechenberg, I., "Measurement of turbulent wall shear stress," Z. Flugwiss. Vol. 11, No. 11, Nov. 1963, pp. $429-438$.

${ }^{2}$ Winter, K. G., "An Outline of the Techniques Available for the Measurement of Skin Friction in Turbulent Boundary Layers," Royal Aircraft Establishment, TMA 1656, Dec. 1975.

${ }^{3}$ Settles, G. S., "Recent Skin Friction Techniques for Compressible Flows," AIAA 86-1099, May 1986.

${ }^{4}$ Naughton, Jonathan D., and Mark Sheplak, "Modern Skin Friction Measurement Techniques: Description, Use, and What to Do with the Data," AIAA 2000-2521, June 2000 .
${ }^{5}$ Hakkinen, Raimo J., "Design and Calibration of a New Surface-Obstacle Skin-Friction and Flow Direction Meter," 16th International Congress on Instrumentation in Aerospace Simulation Facilities, Wright-Patterson AFB, July 18-21, 1995; ICIASF Record, IEEE Publication 95CH3482-7, pp. 7-1 through 7-7.

${ }^{6}$ Bradshaw, P., and N. Gregory, The Determination of Local Turbulent Skin Friction from Observations in the Viscous Sub-layer; Aeronautical Research Council, 20,895; F.M. 2802, Perf. 1753; March, 1959.

${ }^{7}$ Frei, D. and H. Thomann, "Direct measurements of skin friction in a turbulent boundary layer with strong adverse pressure gradient," Journal of Fluid Mechanics, Vol. 101, part 1, pp. 79-95, 1980.

${ }^{8}$ Anderson, John D. Jr., Fundamentals of Aerodynamics, 2nd ed., McGraw-Hill, Inc. New York, New York, 1991, pp. $723-727$.

${ }^{9}$ Clauser, Francis H., "Turbulent Boundary Layers in Adverse Pressure Gradients," Journal of the Aeronautical Sciences, Feb. 1954, pp. 91 - 108.

${ }^{10}$ Soeder, Ronald, H., NASA Lewis 8- By 6-Foot Supersonic Wind Tunnel User Manual, NASA TM 105771 , February 1993.

${ }^{11}$ Bui, Trong T., David L. Oates, and José C. Gonsalez, "Design and Evaluation of a New Boundary-Layer Rake for Flight Testing," AIAA 2000-0503, 38th Aerospace Sciences Meeting and Exhibit, Reno, NV, 10-13 January 2000.

${ }^{12}$ Bradshaw, P. and K. Unsworth, "Comment on 'Evaluation of Preston Tube Calibration Equations in Supersonic Flow,'" AIAA Journal, Vol. 12, No. 9, Sept. 1974, pp. 1293 - 1295.

${ }^{13}$ Allen, Jerry M., Reevaluation of Compressible-Flow Preston Tube Calibrations, NASA TM X-3488, 1977. 


\section{Figures}

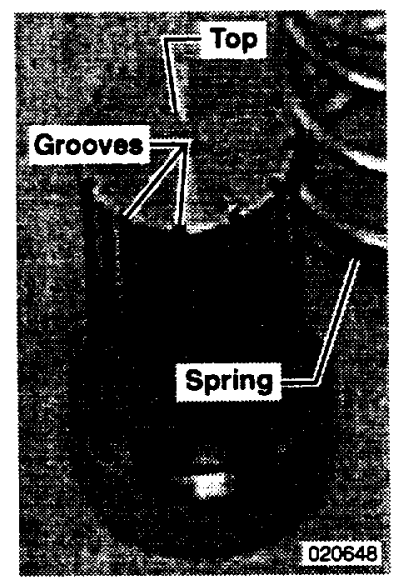

Figure 1. Photograph of adjustable surface obstacle and spring.

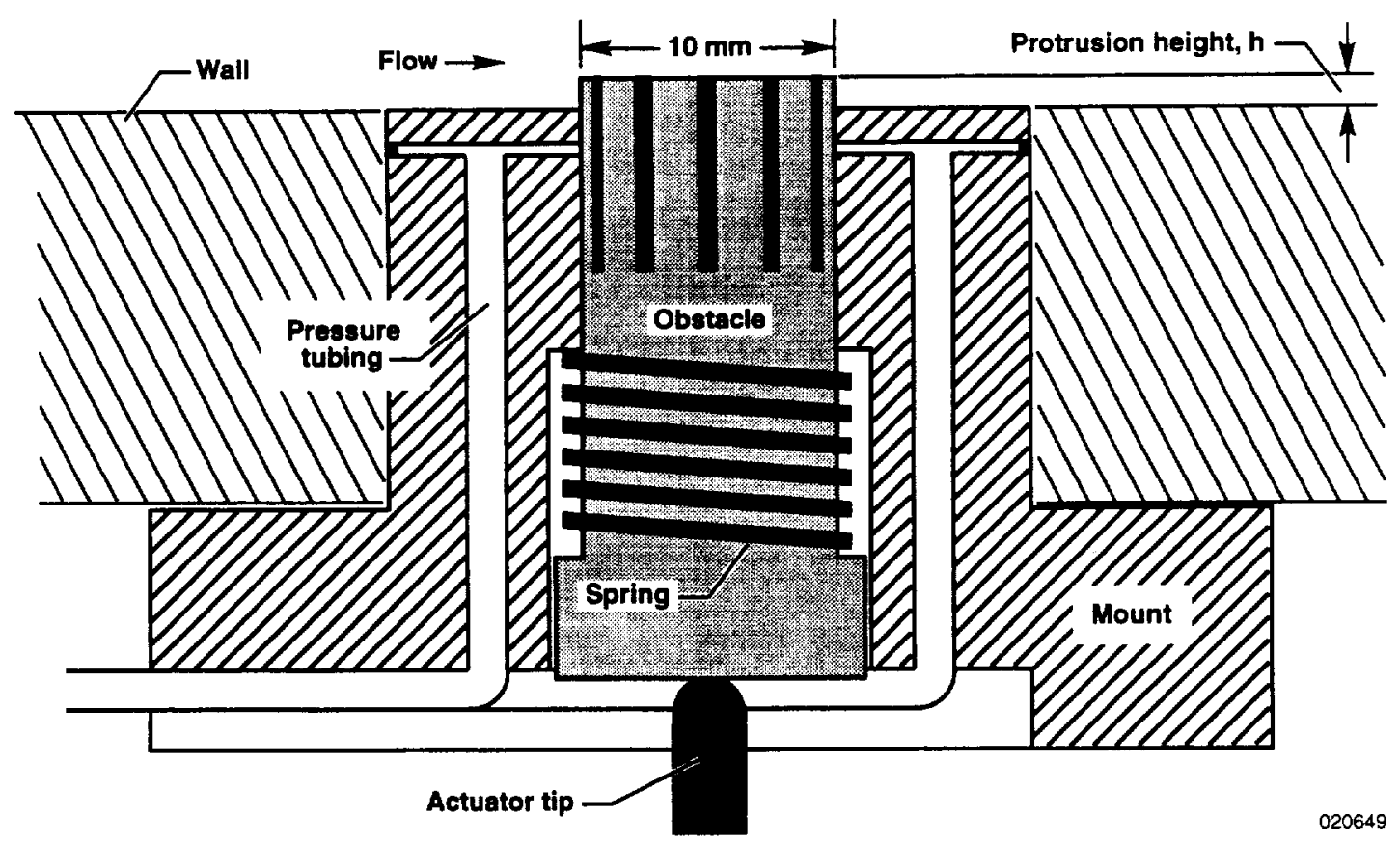

Figure 2. Sketch of obstacle mount showing pressure tubing for two of twelve pressure ports. 


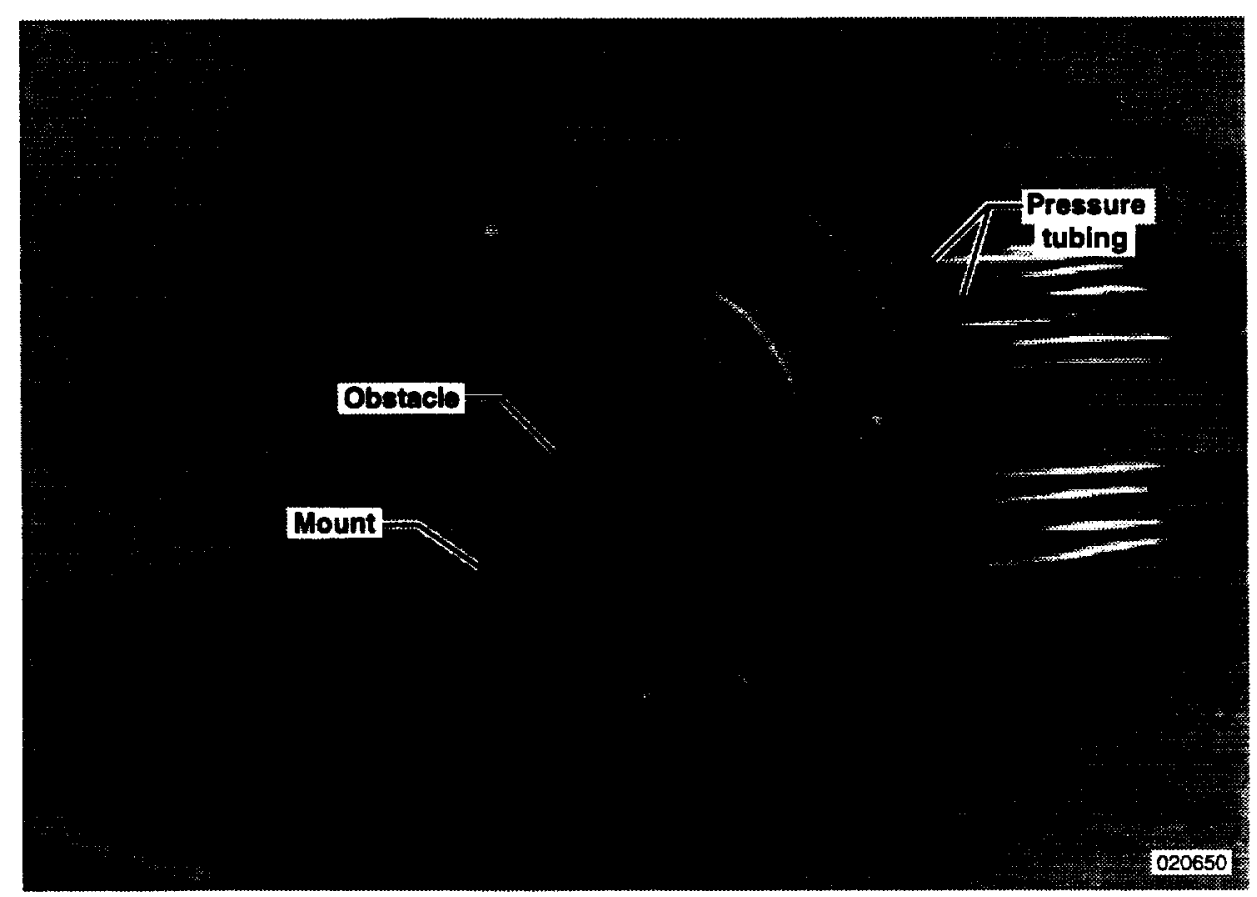

Figure 3. Twelve-port APSO Skin Friction Gage.

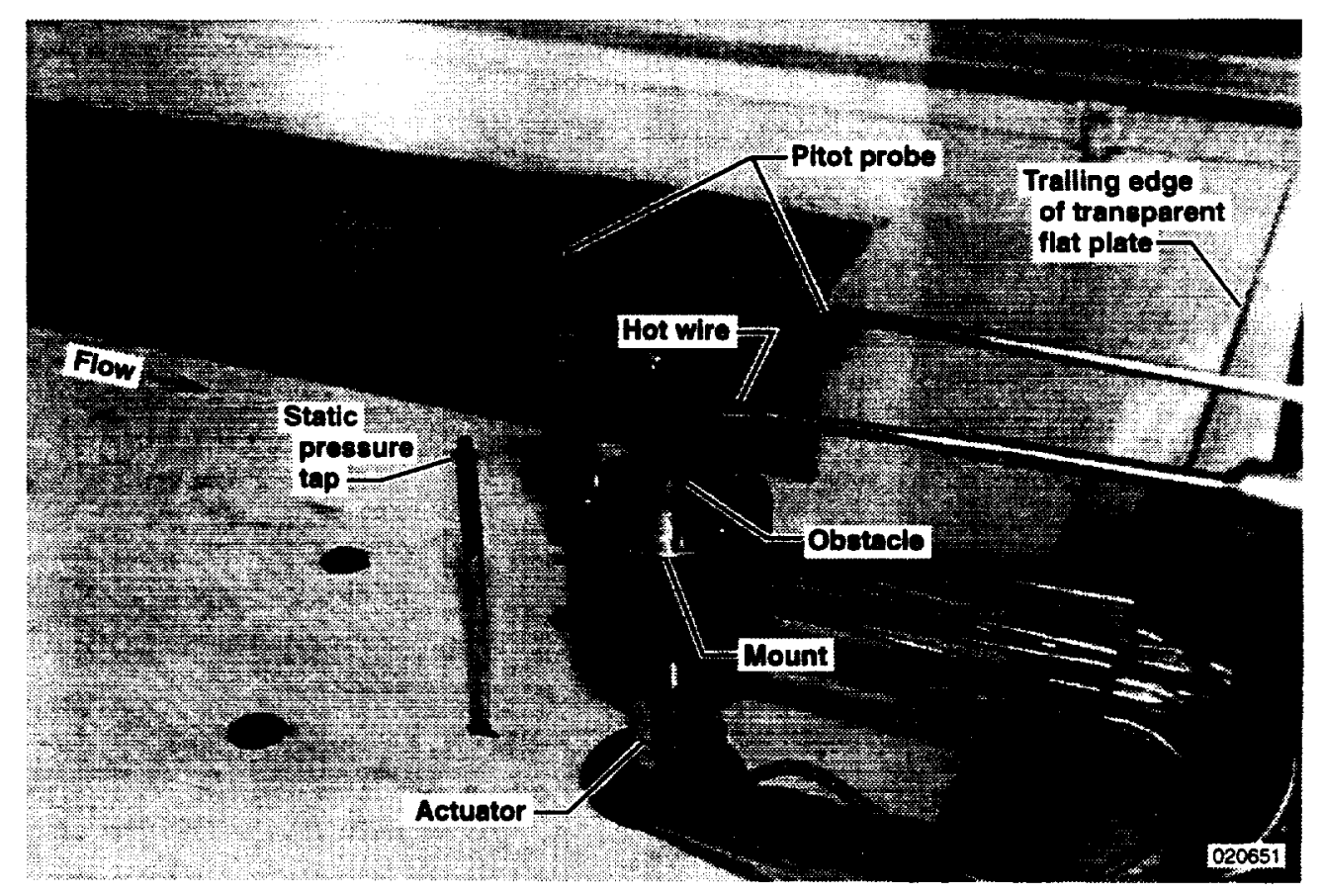

Figure 4. APSO Gage installed in WULSWT. 

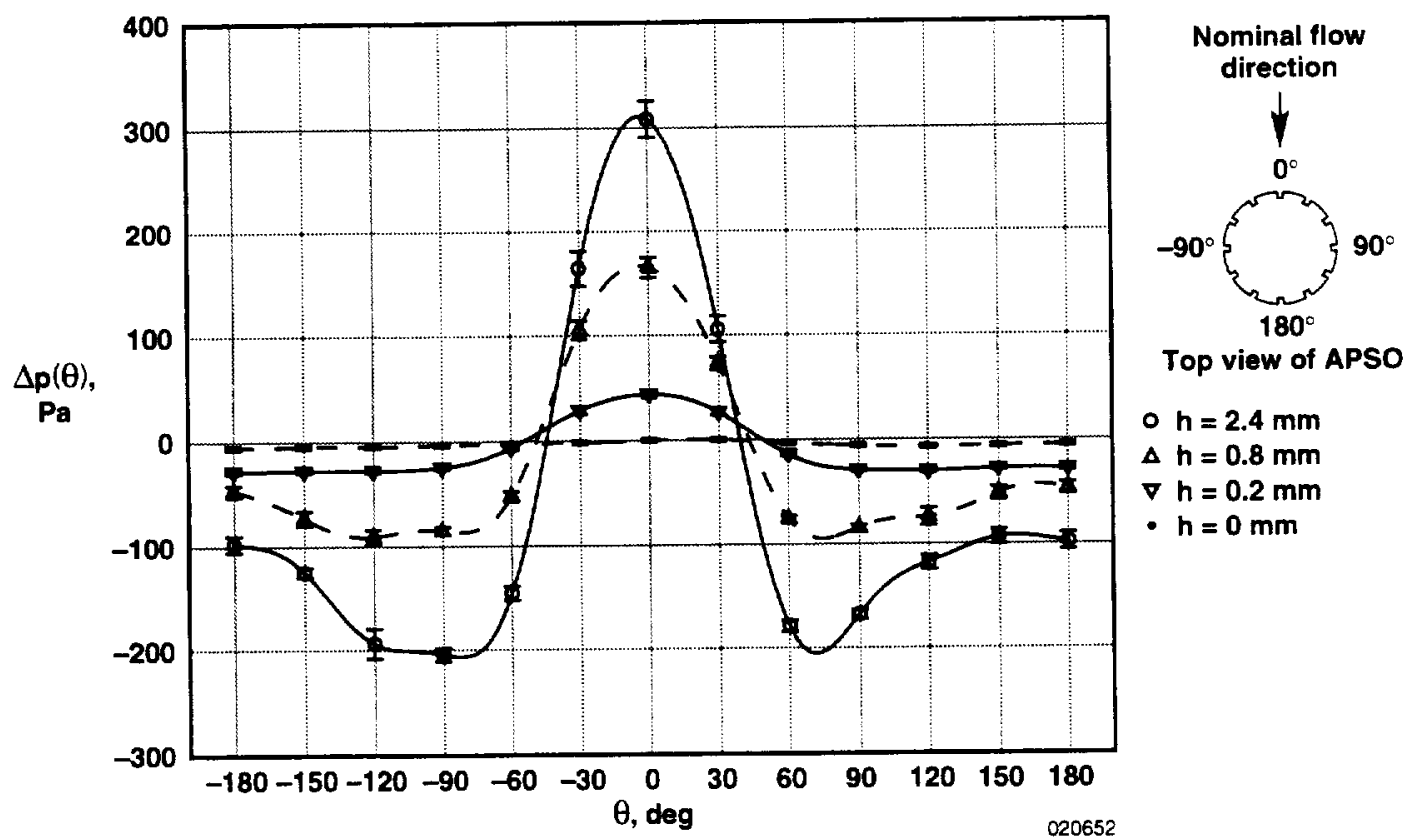

$0 \mathrm{~h}=2.4 \mathrm{~mm}$

$\Delta \mathrm{h}=0.8 \mathrm{~mm}$

$\nabla h=0.2 \mathrm{~mm}$

- $\mathrm{h}=0 \mathrm{~mm}$

Figure 5. Differential pressure distribution for Turbulent Case \#2.

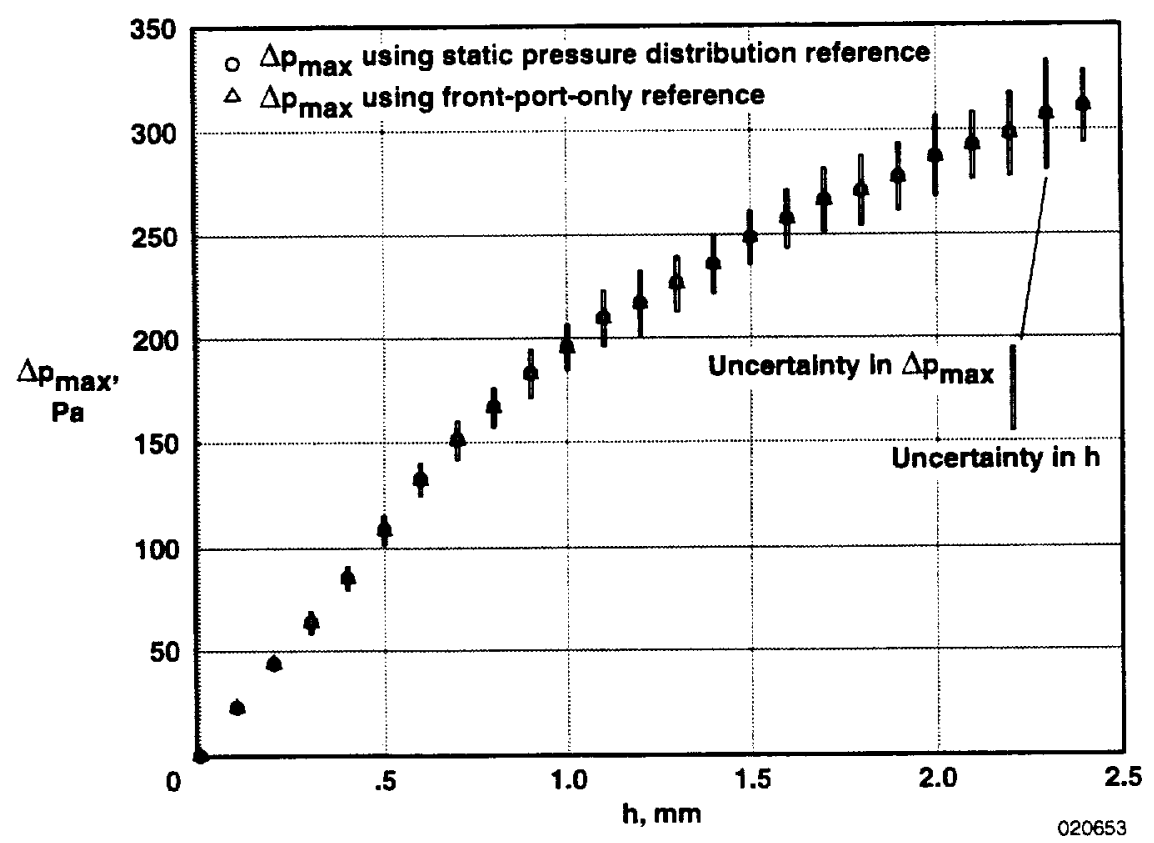

Figure 6. Maximum differential pressure plotted against protrusion height for Turbulent Case \#2. 


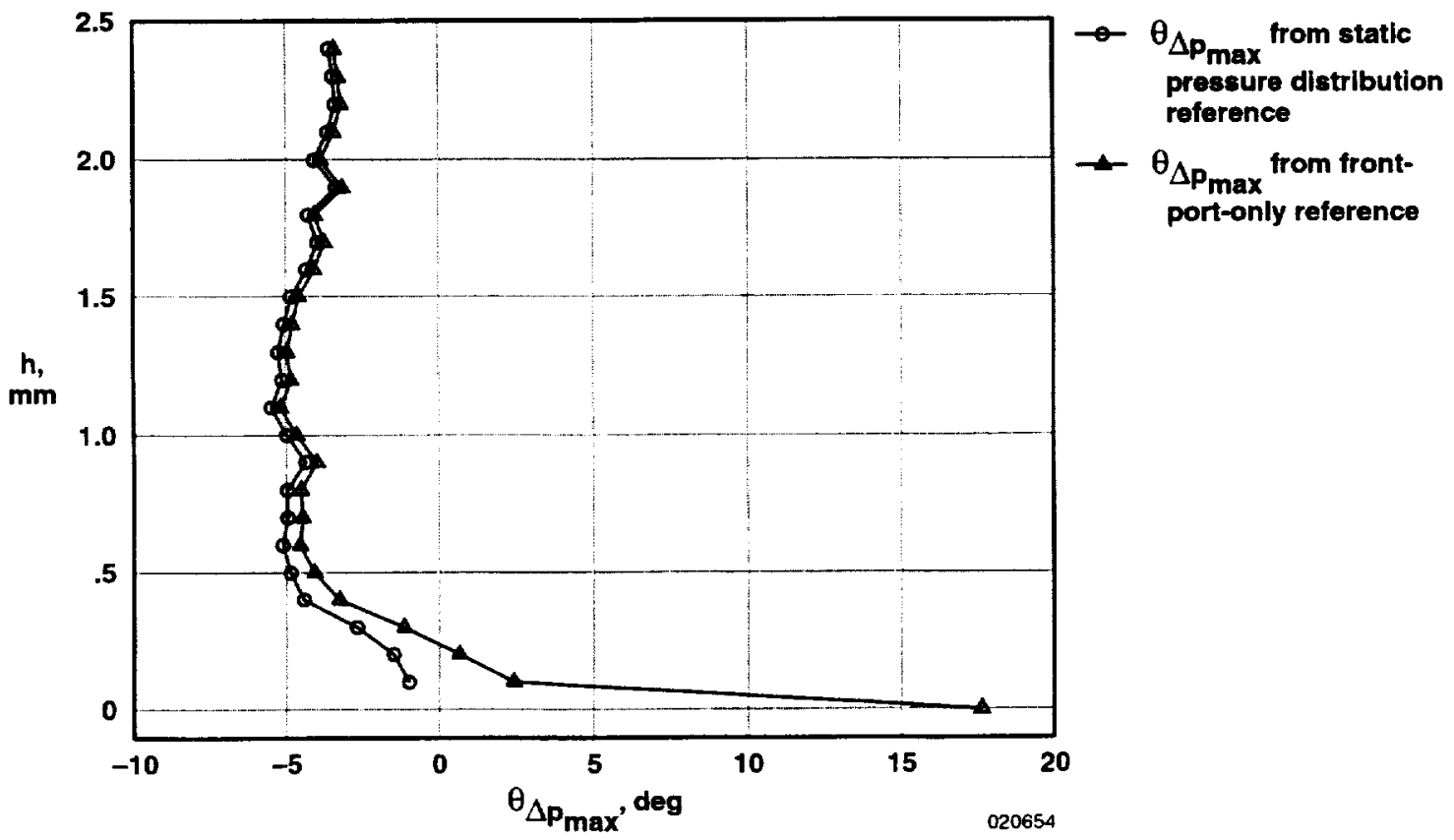

Figure 7. Protrusion height plotted against Fourier-determined location of maximum differential pressure for Turbulent Case \#2. 


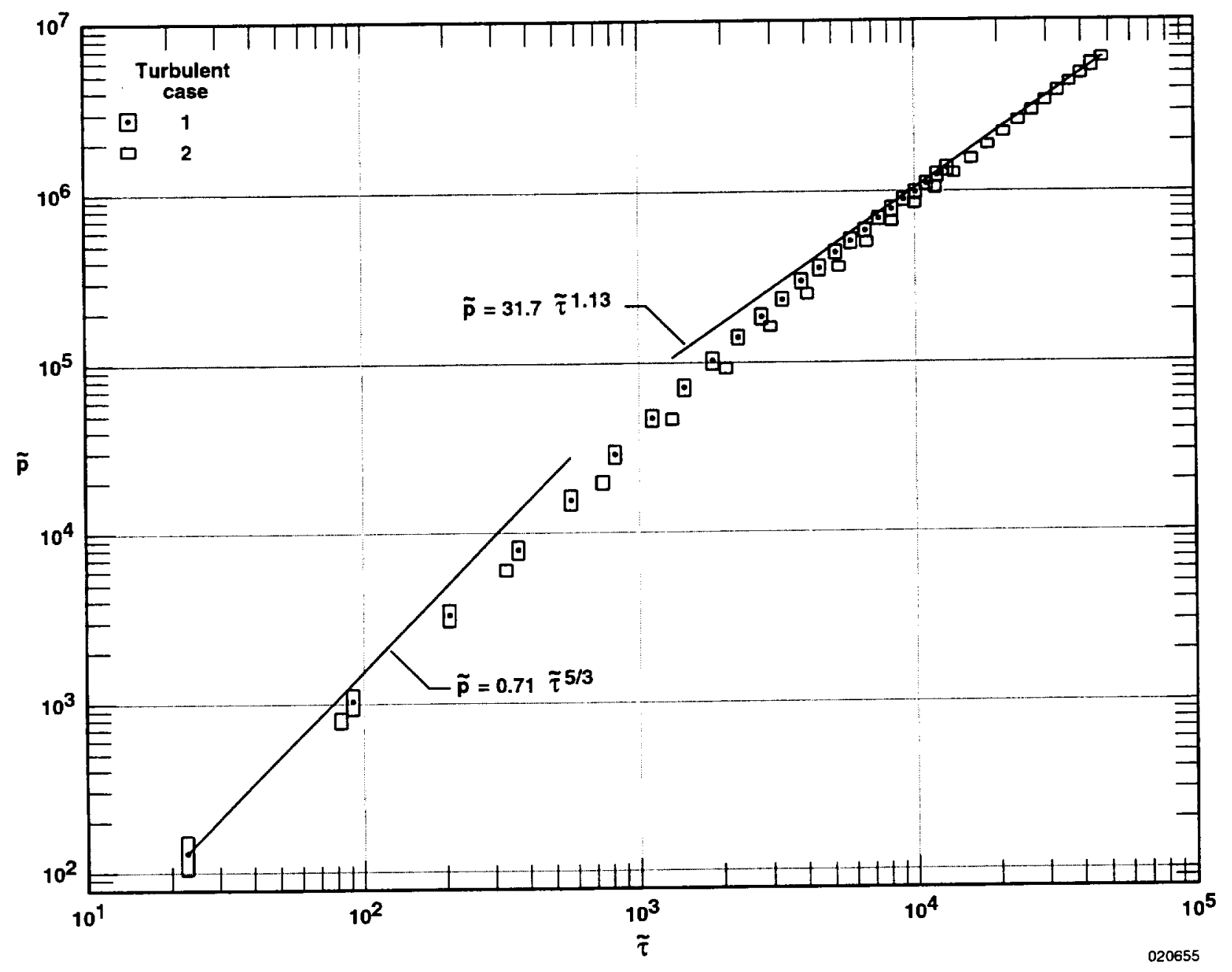

Figure 8. Maximum differential pressure plotted against shear stress (both dimensionless) for turbulent WU test cases. 


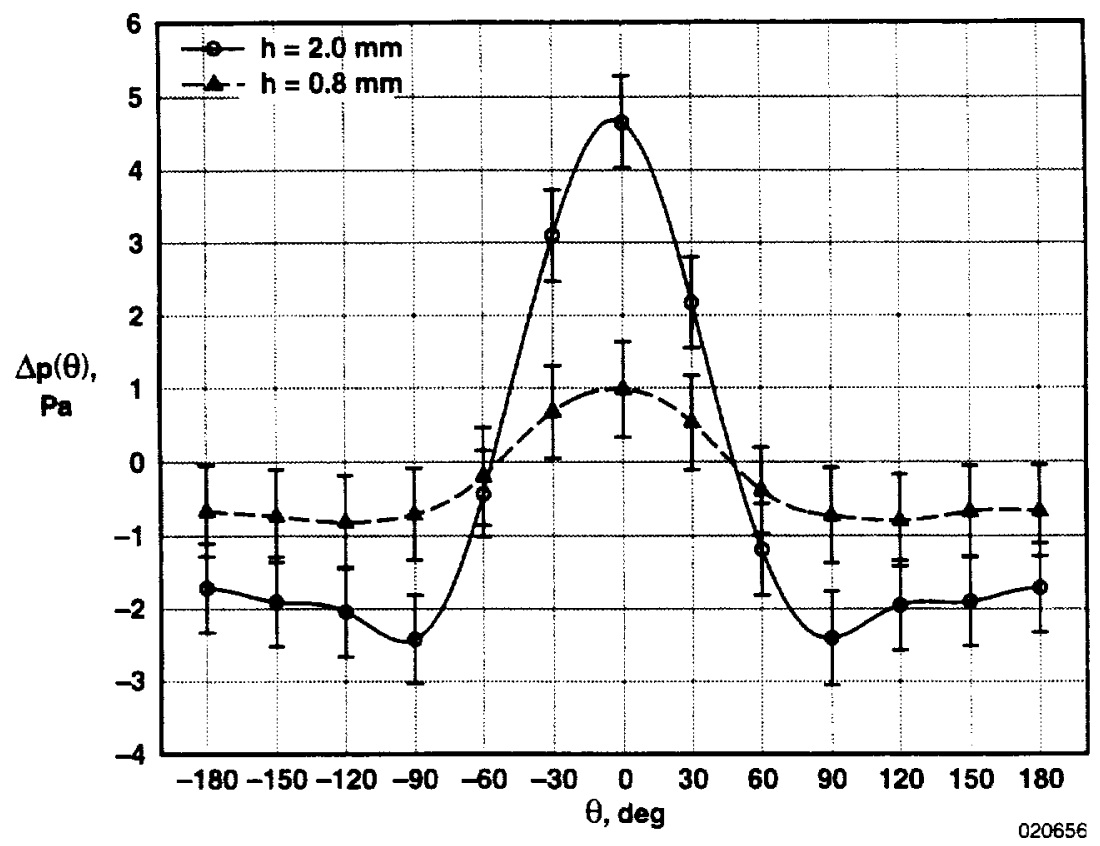

Figure 9. Differential pressure distribution for Laminar Case

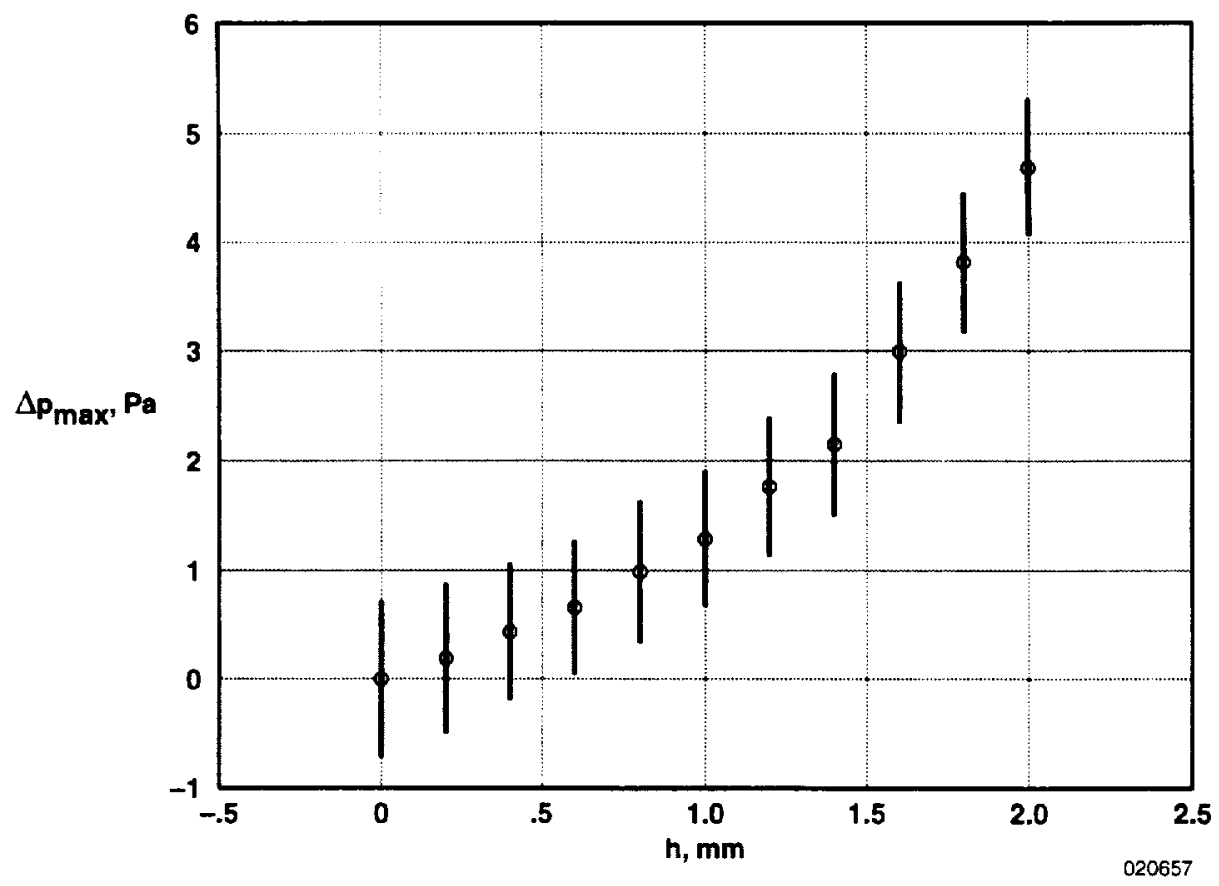

Figure 10. Maximum differential pressure plotted against protrusion height for Laminar Case. 


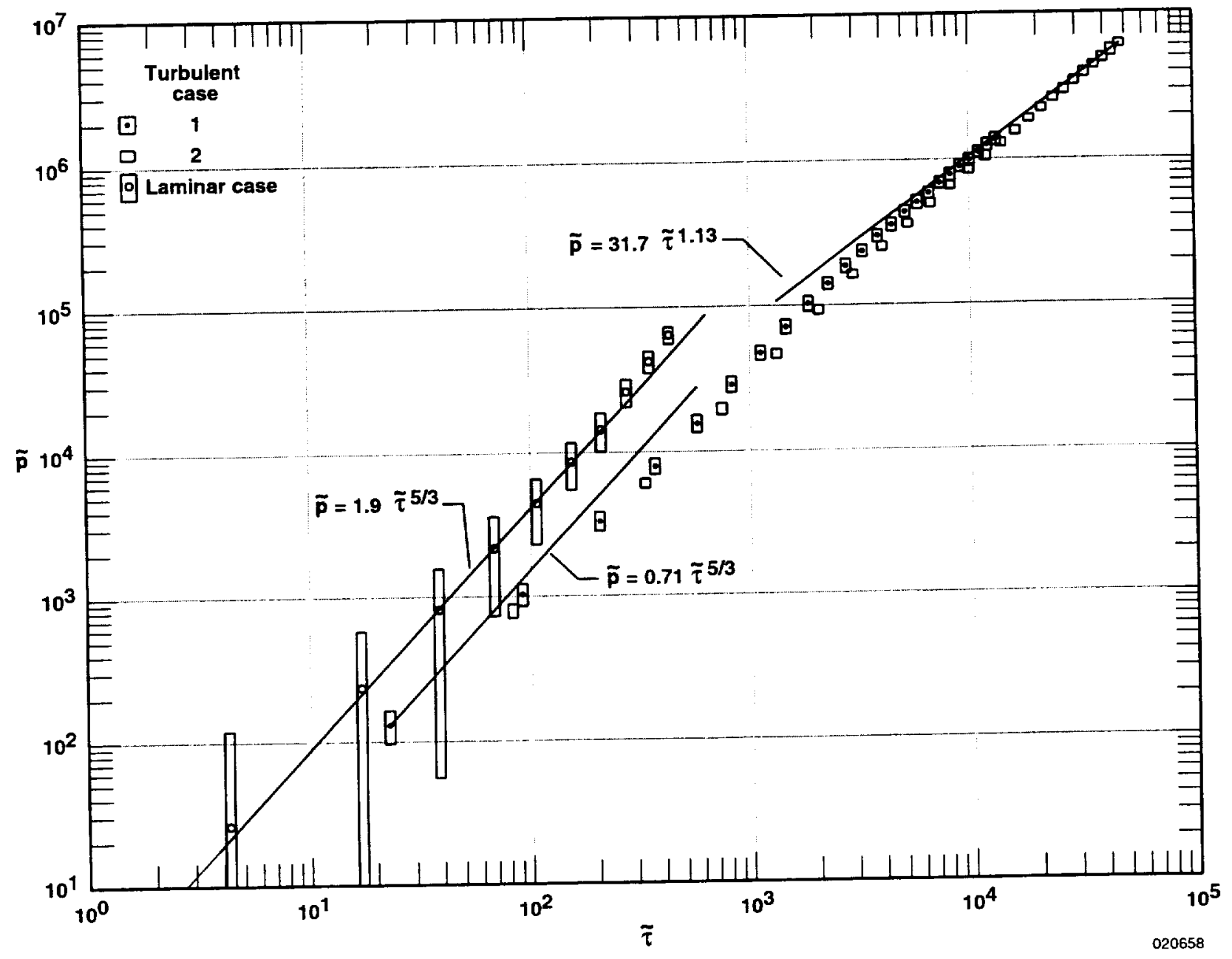

Figure 11. Maximum differential pressure plotted against shear stress (both dimensionless) for all WU test cases. 


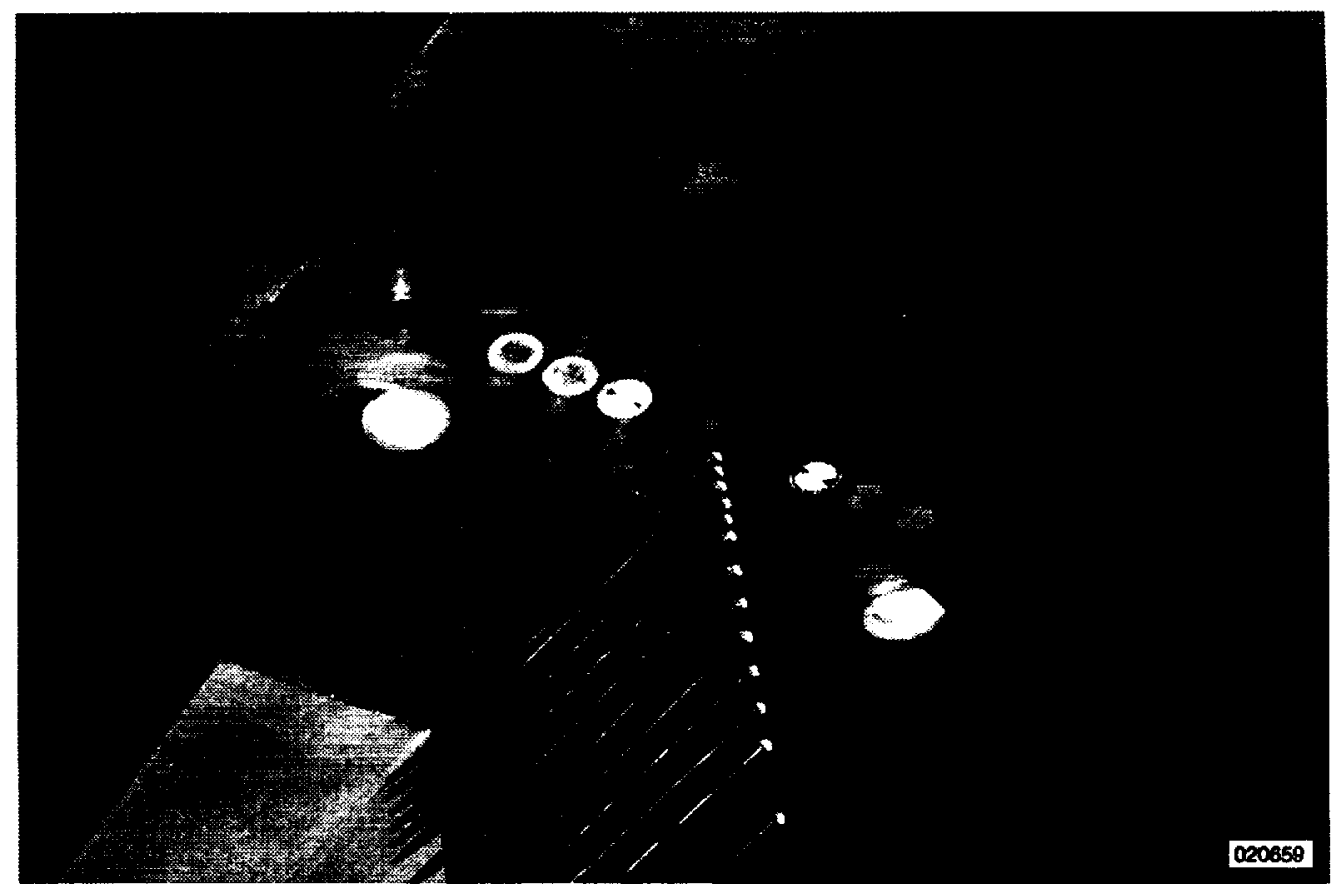

Figure 12. Experiment setup in GRC 8- X 6-Foot Supersonic Wind Tunnel with larger rake.

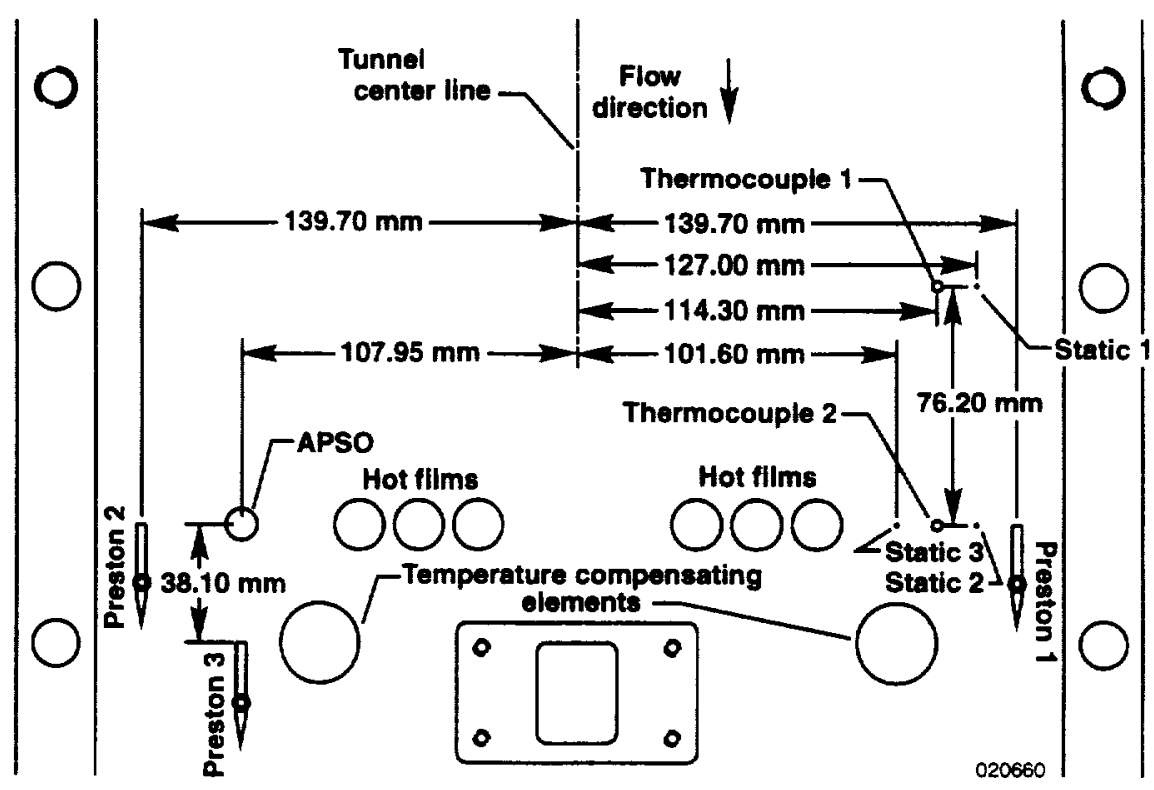

Figure 13. Dimensions for setup in GRC 8- X 6-Foot Supersonic Wind Tunnel. 


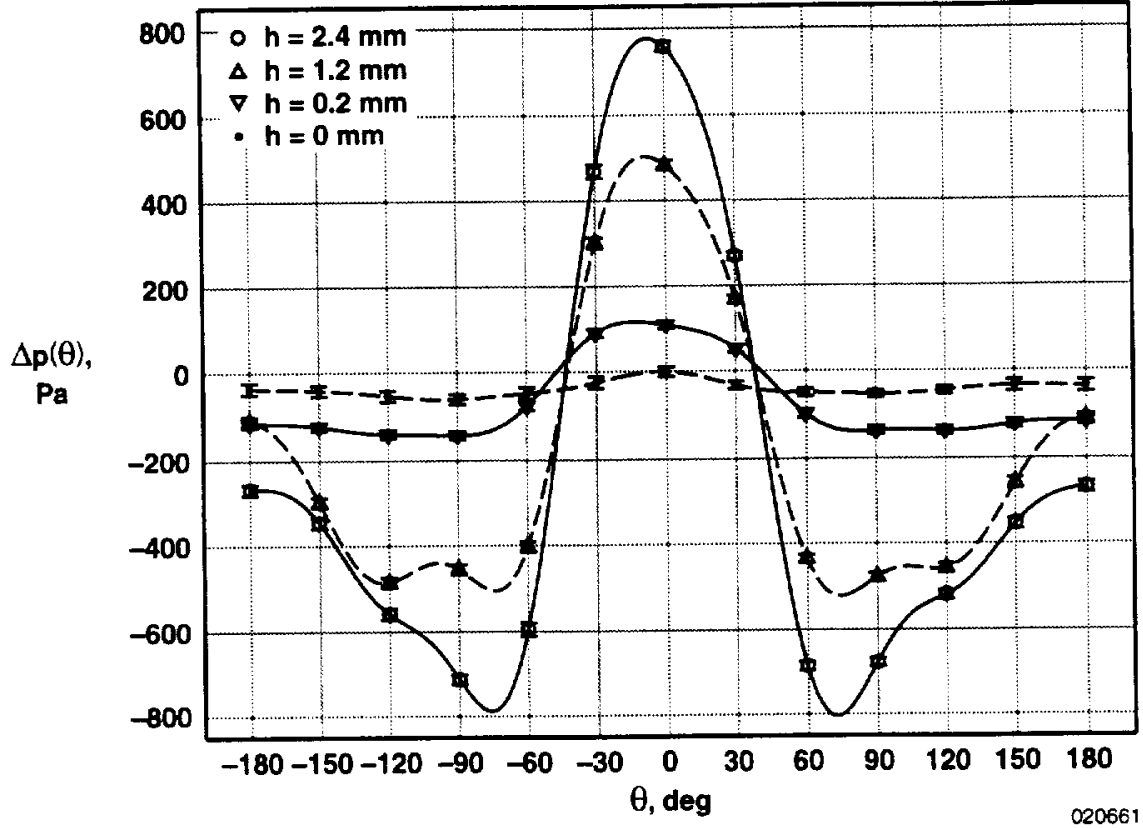

Figure 14. Differential pressure distribution for Mach 0.26.

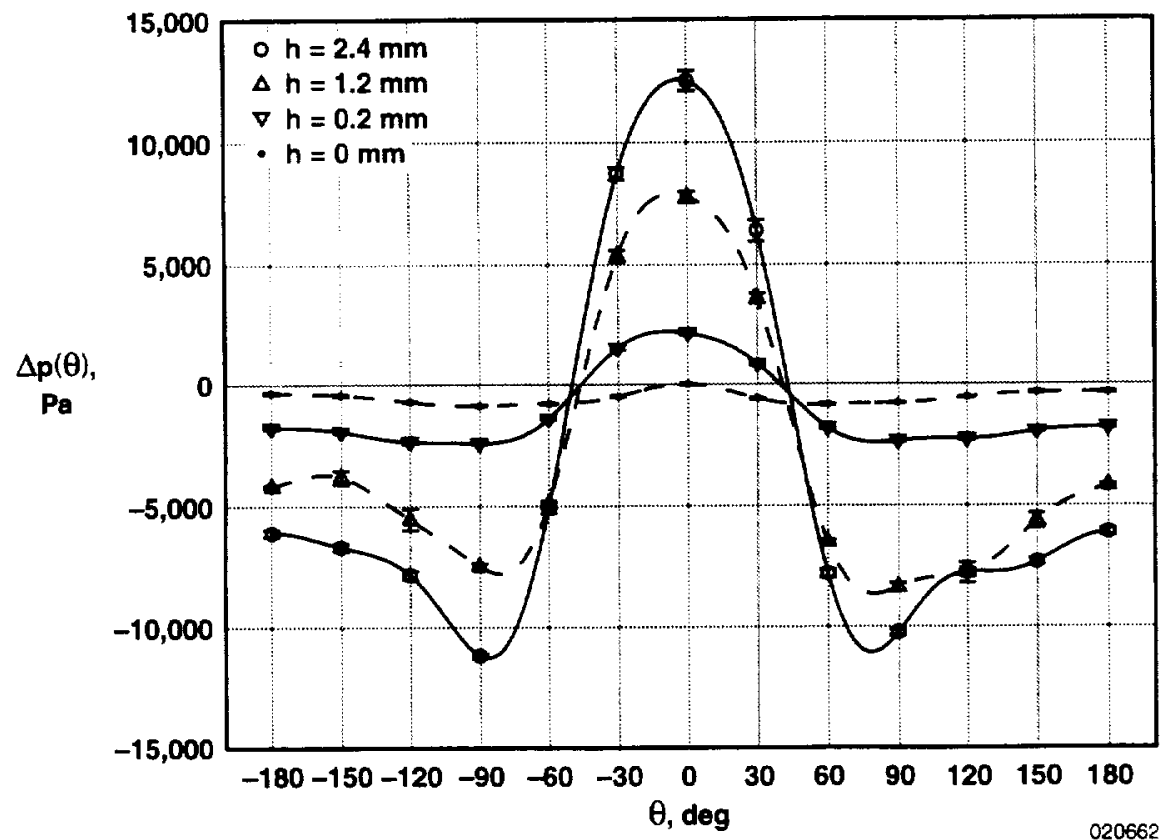

Figure 15. Differential pressure distribution for Mach 1.56. 


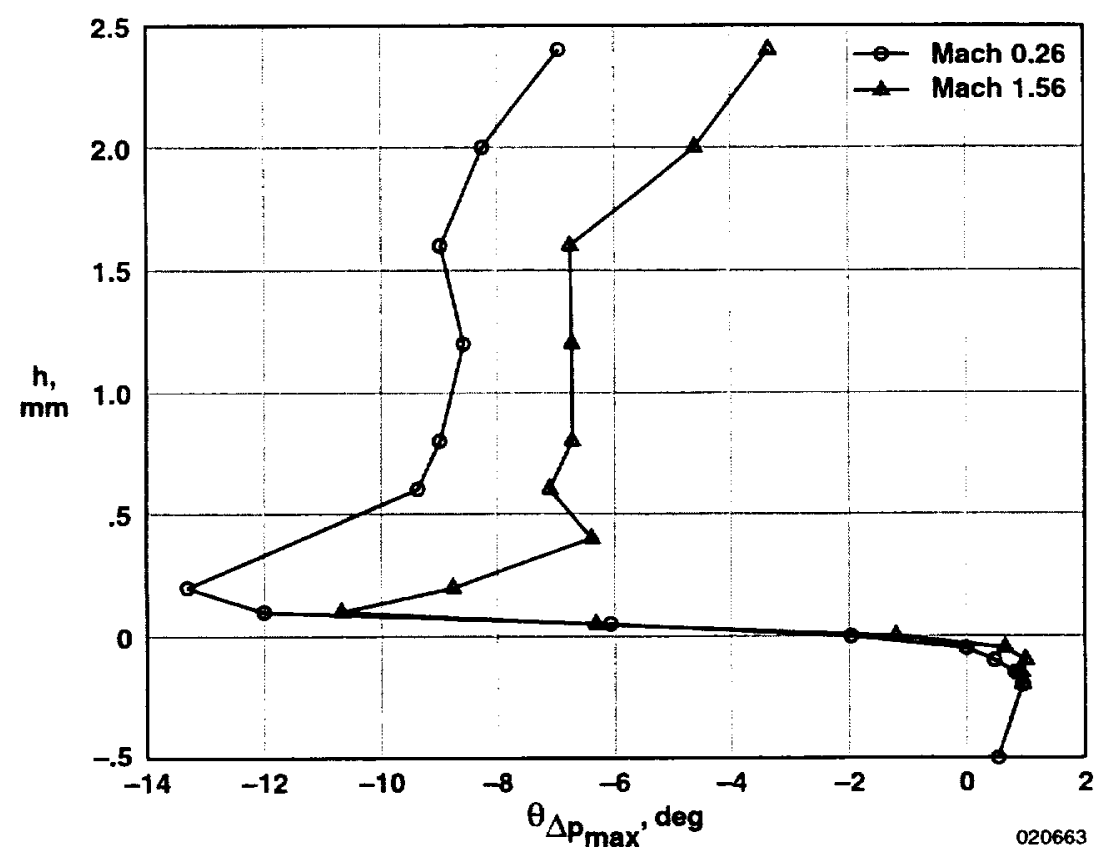

Figure 16. Protrusion height plotted against Fourier-determined location of maximum differential pressure.

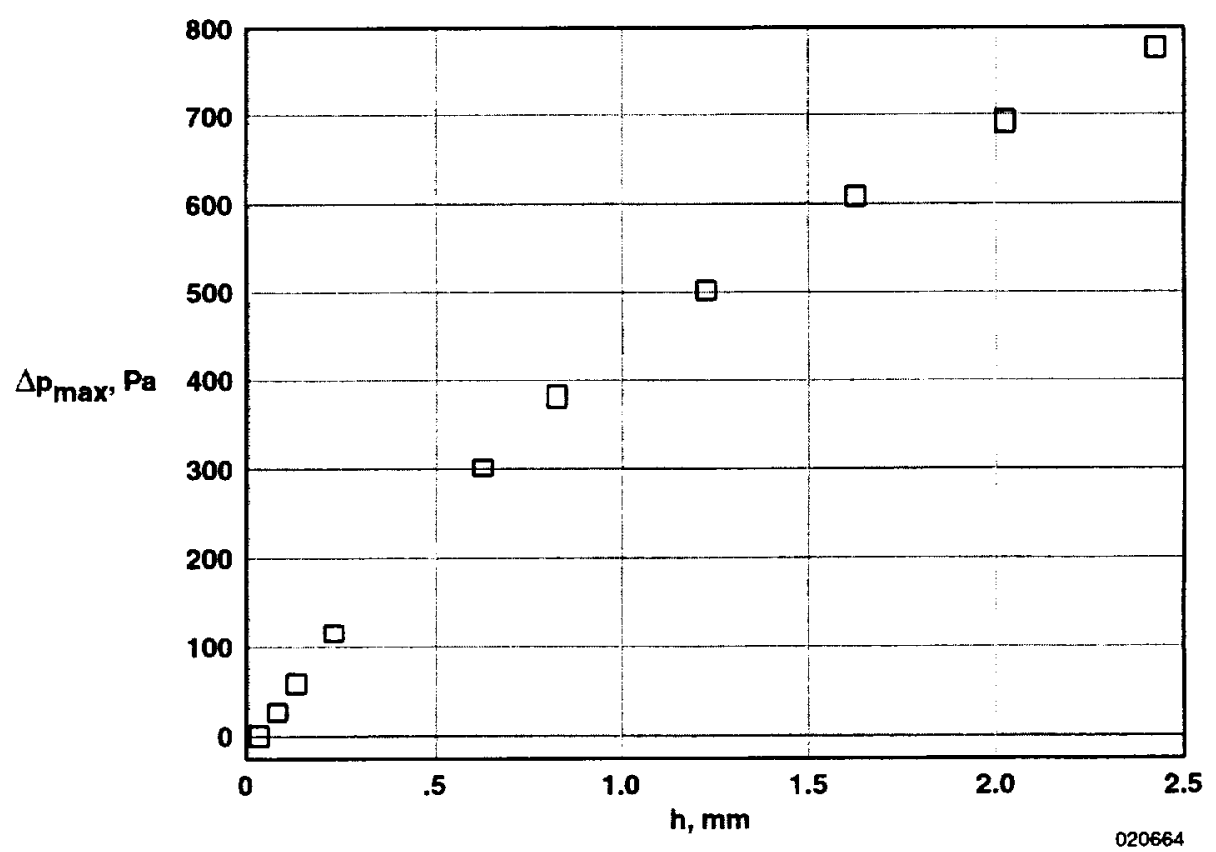

Figure 17. Maximum differential pressure plotted against protrusion height for Mach 0.26 . 


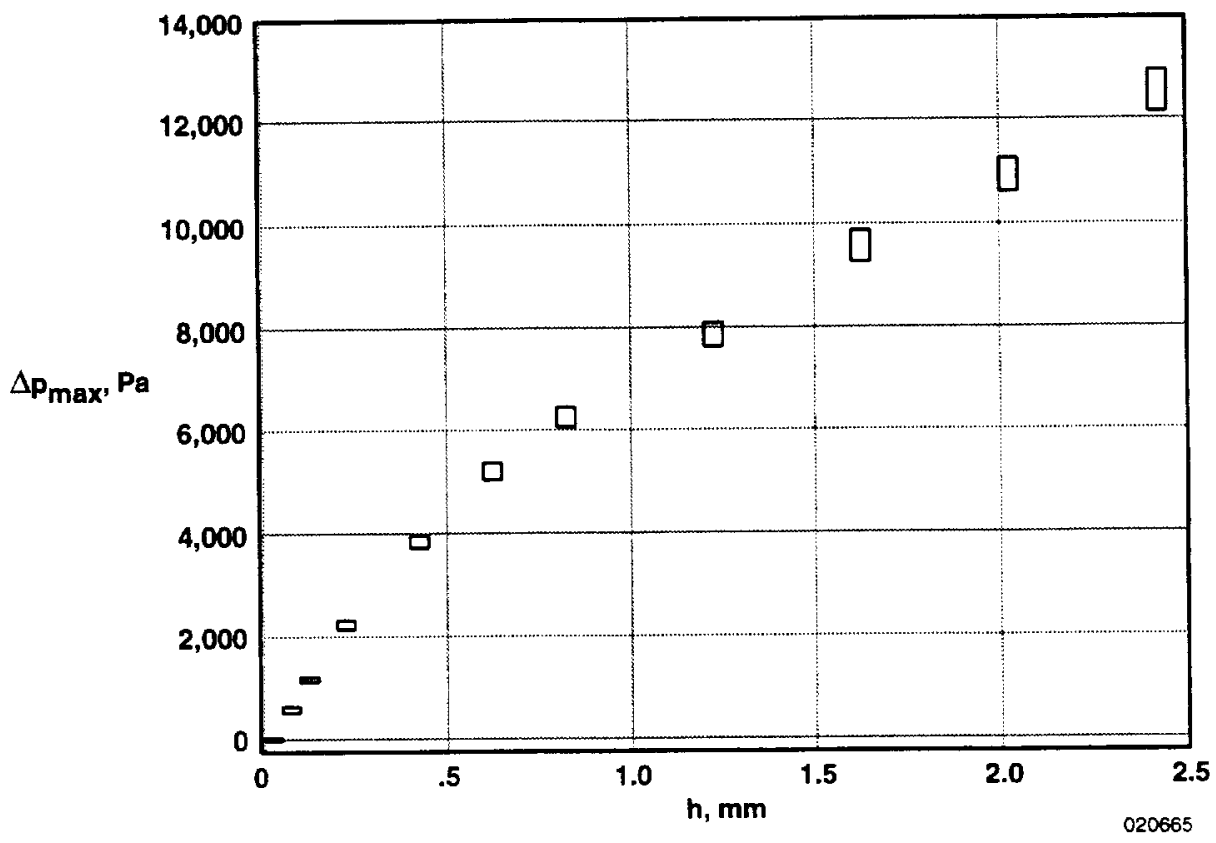

Figure 18. Maximum differential pressure plotted against protrusion height for Mach 1.56 . 


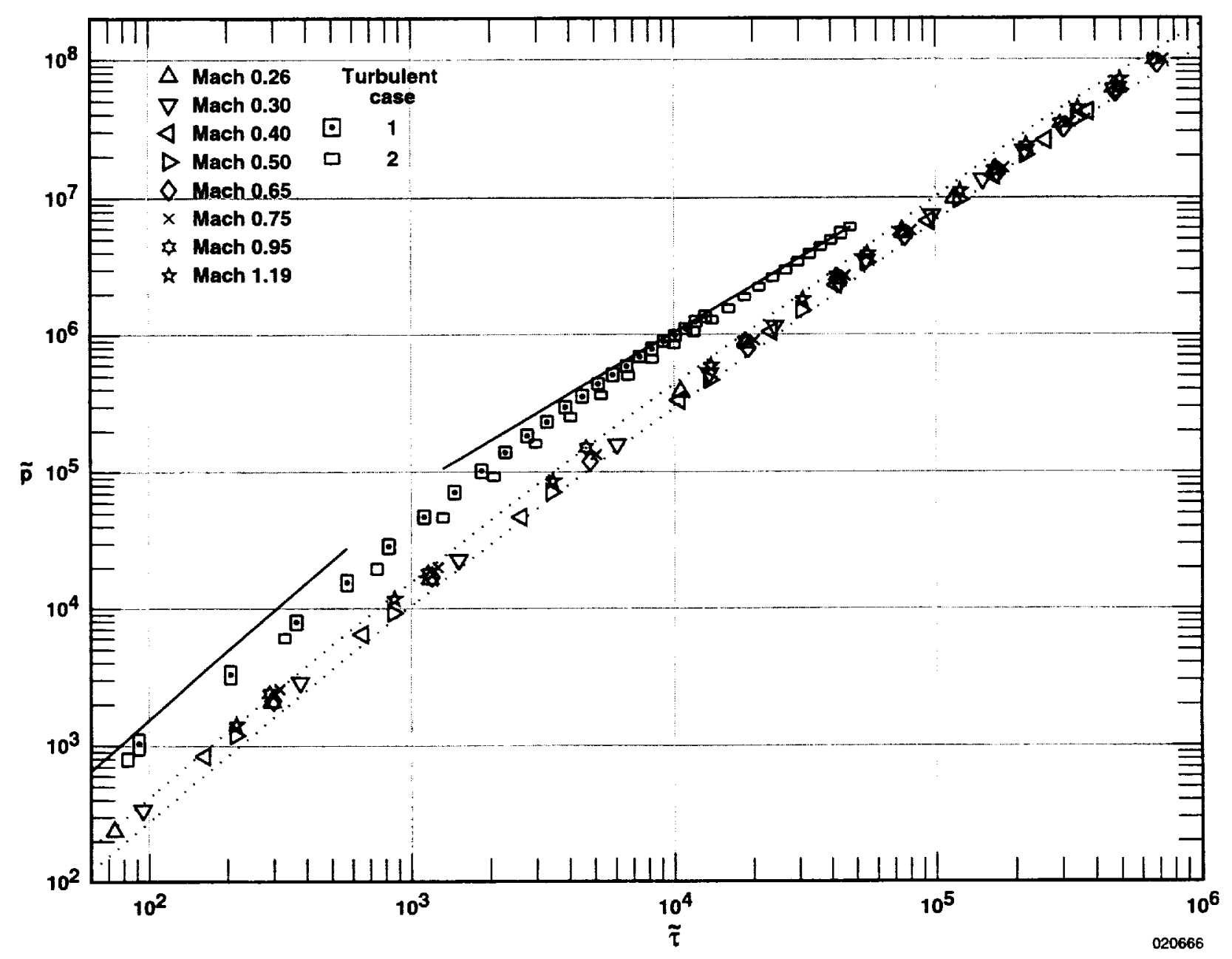

Figure 19. Maximum differential pressure plotted against shear stress (both dimensionless) for Mach $<1.36$. 


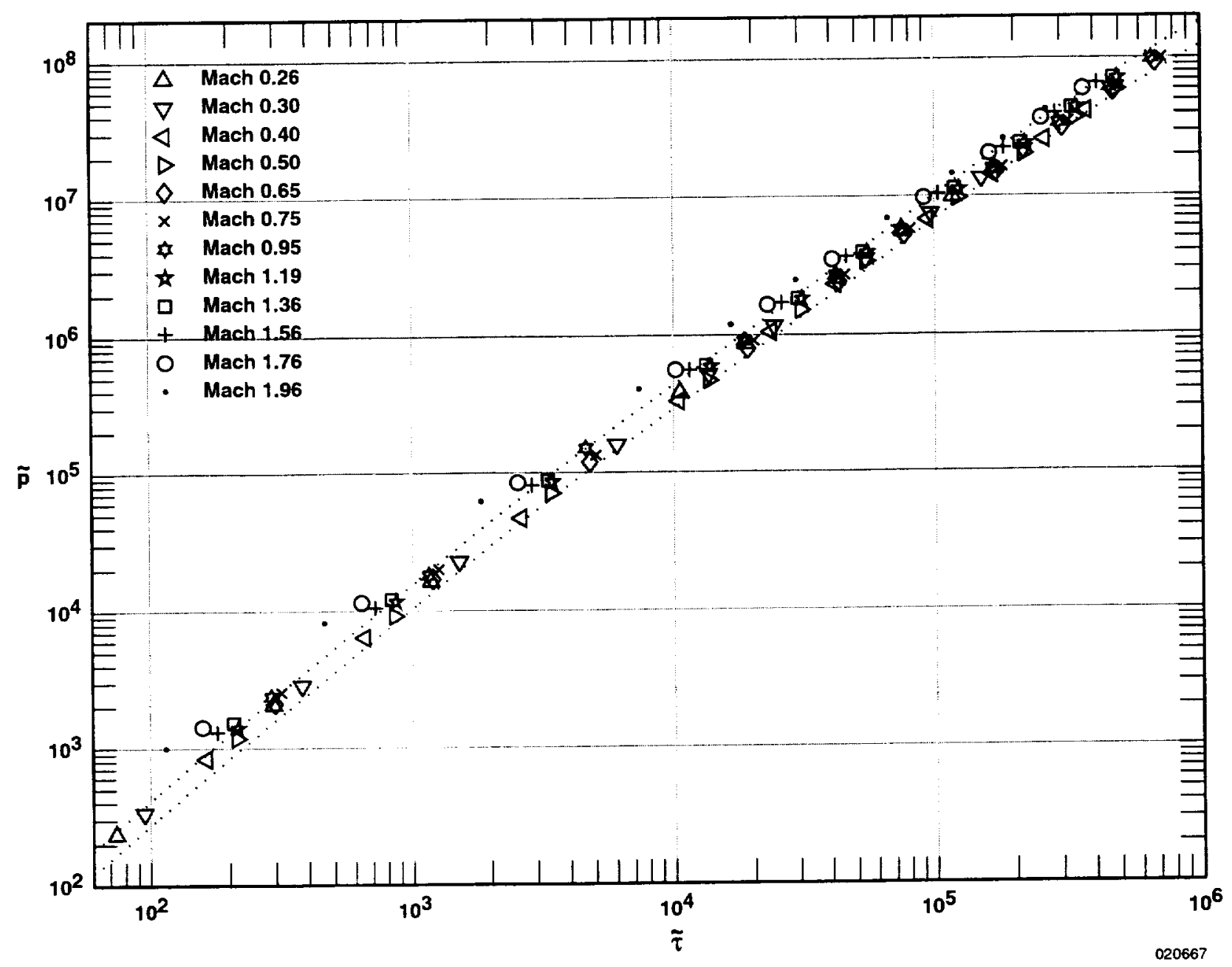

Figure 20. Maximum differential pressure plotted against shear stress (both dimensionless) for all GRC test conditions. 


\begin{tabular}{|c|c|c|c|c|}
\hline \multicolumn{3}{|c|}{ REPORT DOCUMENTATION PAGE } & \multicolumn{2}{|r|}{$\begin{array}{l}\text { Form Approved } \\
\text { OMB No. 0704-0188 }\end{array}$} \\
\hline \multicolumn{5}{|c|}{ 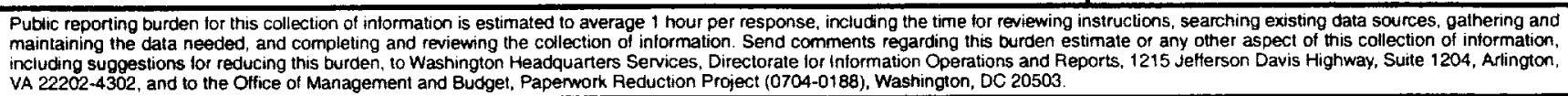 } \\
\hline 1. AGENCY USE ONLY (Leave blank) & \begin{tabular}{l|l} 
2. REPORT DATE \\
February 2003
\end{tabular} & \multicolumn{3}{|c|}{$\begin{array}{l}\text { 3. REPORT TYPE AND DATES COVERED } \\
\text { Technical Memorandum }\end{array}$} \\
\hline \multicolumn{3}{|c|}{$\begin{array}{l}\text { Exploratory Calibration of Adjustable-Protrusion Surface-Obstacle } \\
\text { (APSO) Skin Friction Vector Gage }\end{array}$} & \multicolumn{2}{|c|}{ 5. FUNDING NUMBERS } \\
\hline \multicolumn{5}{|c|}{$\begin{array}{l}\text { 6. AUTHOR(S) } \\
\text { Raimo J. Hakkinen, Jeremy S. Neubauer, Philip J. Hamory, Trong T. Bui, } \\
\text { and Gregory K. Noffz }\end{array}$} \\
\hline $\begin{array}{l}\text { 7. PERFORMING ORGANIZATION N. } \\
\text { NASA Dryden Flight } \mathrm{R} \\
\text { P.O. Box } 273 \\
\text { Edwards, Califormia } 93\end{array}$ & $\begin{array}{l}\text { E(S) AND ADDRESS(ES) } \\
\text { earch Center } \\
3-0273\end{array}$ & & \multicolumn{2}{|c|}{ H-2519 } \\
\hline \multicolumn{2}{|c|}{$\begin{array}{l}\text { National Aeronautics and Space Administration } \\
\text { Washington, DC 20546-0001 }\end{array}$} & & \multicolumn{2}{|c|}{ NASA/TM-2003-210739 } \\
\hline \multicolumn{5}{|c|}{$\begin{array}{l}\text { 11. SUPPLEMENTARY NOTES } \\
\text { Also presented at } 4 \text { 1st AIAA Aerospace Sciences Meeting and Exhibit, Reno, NV, January 6-9, 2003, AlAA-2003-0740. Raimo J. Hakkinen and Jeremy S } \\
\text { Neubauer, Washington University, St. Louis, Missouri; Philip J. Hamory, Trong T. Bui, and Gregory K. Noffz, NASA Dryden Flight Research Center } \\
\text { Edwards. Califormia }\end{array}$} \\
\hline \multicolumn{3}{|c|}{$\begin{array}{l}\text { Unclassified-Unlimited } \\
\text { Subject Category } 35 \\
\text { This report is available at http://www.dfrc.nasa.gov/DTRS/ }\end{array}$} & \multicolumn{2}{|c|}{ 12b. DISTRIBUTION CODE } \\
\hline \multicolumn{5}{|c|}{$\begin{array}{l}\text { The design of an adjustable-protrusion surface-obstacle (APSO) skin friction vector gage is presented. Results } \\
\text { from exploratory calibrations conducted in laminar and turbulent boundary layers at the Washington University } \\
\text { Low-Speed Wind Tunnel and for turbulent boundary layers at speeds up to Mach } 2 \text { on the ceiling of the NASA } \\
\text { Glenn Research Center 8- X 6-ft Supersonic Wind Tunnel are also discussed. The adjustable-height gage was } \\
\text { designed to yield both the magnitude and direction of the surface shear stress vector and to measure the local } \\
\text { static pressure distribution. Results from the NASA test show good correlation for subsonic and low supersonic } \\
\text { conditions covering several orders of magnitude in terms of the adopted similarity variables. Recommendations } \\
\text { for future work in this area consist of identifying the physical parameters responsible for the disagreement } \\
\text { between the university and NASA data sets, developing a compressibility correction specific to the APSO } \\
\text { geometry, and examining the effect that static pressure distribution and skewed boundary layers have on the } \\
\text { results from the APSO. }\end{array}$} \\
\hline \multirow{2}{*}{\multicolumn{4}{|c|}{$\begin{array}{l}\text { 14. SUBJECT TERMS } \\
\text { skin friction, friction measurement, shear stress, stress measurement, boundary } \\
\text { layer, Preston tube, pressure measurement, calibrating, wind tunnel tests }\end{array}$}} & $\begin{array}{l}\text { 15. NUMBER OF PAGES } \\
27\end{array}$ \\
\hline & & & & $\begin{array}{l}\text { 16. PRICE CODE } \\
\text { RI1 }\end{array}$ \\
\hline $\begin{array}{l}\text { 17. SECURITY CLASSIFICATION } \\
\text { OF REPORT }\end{array}$ & $\begin{array}{l}\text { 18. SECURITY CLASSIFICATION } \\
\text { OF THIS PAGE }\end{array}$ & $\begin{array}{l}\text { 19. SECURITY CLASSIF } \\
\text { OF ABSTRACT }\end{array}$ & & 20. LIMTAATION OF ABSTRACT \\
\hline Unclassified & Unclassified & & & Unlimited \\
\hline
\end{tabular}


National Aeronautics and

Space Administration

Code JTT

Washington, D.C. 20546-0001

SPECIAL FOURTH-CLASS RATE POSTAGE AND FEES PAID

NASA

PERMIT No G27

USA

Official Business

Penalty for Private Use, \$300

NASA

POSTMASTER: If Undeliverable (Section 158

Postal manuaj) Do Not Retum 